\title{
Structural Studies of Cesium, Lithium/Cesium, and Sodium/Cesium Bis(trimethylsilyl)amide (HMDS) Complexes
}

\author{
Ana I. Ojeda-Amador, Antonio J. Martínez-Martínez, Alan R. Kennedy, and Charles T. O’Hara* \\ WestCHEM, Department of Pure and Applied Chemistry, University of Strathclyde, Glasgow, G1 1XL, United Kingdom \\ Supporting Information
}

ABSTRACT: Reacting cesium fluoride with an equimolar $n$-hexane solution of lithium bis(trimethylsilyl)amide (LiHMDS) allows the isolation of CsHMDS (1) in $80 \%$ yield (after sublimation). This preparative route to $\mathbf{1}$ negates the need for pyrophoric Cs metal or organocesium reagents in its synthesis. If a 2:1 LiHMDS:CsF ratio is employed, the heterobimetallic polymer $\left[\mathrm{LiCs}(\mathrm{HMDS})_{2}\right]_{\infty} 2$ was isolated ( $57 \%$ yield). By combining equimolar quantities of $\mathrm{NaHMDS}$ and CsHMDS in hexane/toluene [toluene-NaCs(HMDS) $]_{\infty} 3$ was isolated (62\% yield). Attempts to prepare the corresponding potassiumcesium amide failed and instead yielded the known monometallic polymer [toluene. $\mathrm{Cs}(\mathrm{HMDS})]_{\infty}$ 4. With the aim of expanding the structural diversity of Cs(HMDS) species, 1 was reacted with several different Lewis basic donor molecules of varying denticity, namely, $(R, R)-N, N, N^{\prime}, N^{\prime}$-tetramethylcyclohexane-1,2-diamine [(R,R)-TMCDA] and $N, N, N^{\prime}, N^{\prime}$-tetra-

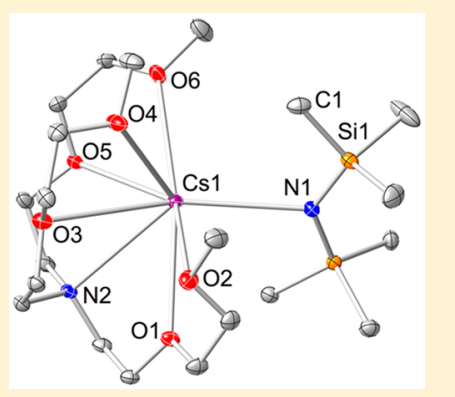
methylethylenediamine (TMEDA), $N, N, N^{\prime}, N^{\prime \prime}, N^{\prime \prime}$-pentamethyldiethylenetriamine (PMDETA), tris[2-(dimethylamino)ethyl]amine $\left(\mathrm{Me}_{6}\right.$-TREN) and tris[2-(2-methoxyethoxy)ethyl]amine (TMEEA). These reactions yielded dimeric [donor-NaCs$\left.(\mathrm{HMDS})_{2}\right]_{2}$ 5-7 [where donor is $(R, R)$-TMCDA, TMEDA and PMDETA respectively], the tetranuclear "open"-dimer [ $\left\{\mathrm{Me}_{6}\right.$ TREN.Cs(HMDS $\left.)\}_{2}\{\mathrm{Cs}(\mathrm{HMDS})\}_{2}\right] \mathbf{8}$ and the monomeric [TMEEA.Cs(HMDS)] 9. Complexes 2, 3, and 5-9 were characterized by X-ray crystallography and in solution by multinuclear NMR spectroscopy.

\section{INTRODUCTION}

Lithium secondary amides are among the most widely utilized reagents in modern synthesis. In particular, the "utility amides" lithium bis(trimethylsilyl)amide (LiHMDS), lithium diisopropylamide (LDA), and lithium 2,2,6,6-tetramethylpiperidide (LiTMP) are essential tools in most synthetic laboratories as non-nucleophilic strong Brønsted bases. ${ }^{1}$ LiHMDS (most pertinent to this paper) itself has had a prominent role in organic synthesis. ${ }^{2}$ Its utility is attributed not only to its Brønsted basic character, but also to the special profile of the TMS group, which makes LiHMDS soluble in a wide range of nonpolar organic solvents. ${ }^{3}$ This and other features such as the lack of $\beta$-hydrogens ${ }^{4}$ and the weaker basicity of LiHMDS compared to LiTMP and LDA [pK (LiHMDS) $=24.37 ; \mathrm{pK}$ $(\mathrm{LDA})=35.41 ; \mathrm{pK}(\mathrm{LiTMP})=35.53]^{5}$ enables the facile isolation of reactive species, allowing access to structural models providing a basis for the clear understanding of structure/reactivity relationships. ${ }^{6}$ In this context, the solution behavior of the alkali metal secondary amides of HMDS has focused primarily on the lithium salt [mainly using diffusion ordered spectroscopy (DOSY) techniques ${ }^{7}$ and isotopically enriched ${ }^{6} \mathrm{Li} /{ }^{15} \mathrm{~N}$ samples to deeply understand their aggregation state $]^{8}$ and the solid state structural chemistry of lithium, and its sodium congener have been reported in both the absence and the presence of synthetically important solvents. In 1969, Böttcher et al. reported the solid state structure of solvent-free LiHMDS, showing it existed as a $\mathrm{LiN}$ cyclotrimer. ${ }^{9}$ This oligomer was discussed further in an Atwood et al. study 10 years later. ${ }^{10}$ The solid state structure of
NaHMDS was reported first by Grüning and Atwood as a polymeric chain of alternating $\mathrm{N}$ and $\mathrm{Na}$ atoms ${ }^{11}$ and later by Nöth ${ }^{12}$ and Driess ${ }^{13}$ as a near-planar cyclotrimer. These compounds can behave as Lewis acids; the choice of donor solvent significantly affects the stabilization and final aggregation state of the complex. An increased reactivity is often noticed when a Lewis donor base is used in the reaction mixture, decreasing the aggregation state and increasing the solubility of the metal amide. ${ }^{14}$ A review published in 2013 by Mulvey et al. highlights the structural chemistry of the known lithium, sodium, and potassium utility amides in the absence or in the presence of the most synthetically significant donor solvents ${ }^{1}$ showing that a complex relationship exists between aggregation state and solvation. However, much less is known about the structural chemistry of heavier alkali metal HMDS bases, such as CsHMDS, in stark contrast to the increasing utility of this reagent in synthesis for metalation, ${ }^{15}$ cyclization, ${ }^{16}$ and nucleophilic trifluoromethylation reactions. ${ }^{17}$ Our group recently published a study where CsHMDS is obtained as a byproduct, produced via salt metathesis involving NaHMDS and cesium halides and interacting with the ligand present in solution. ${ }^{18}$ This absence of structural information may be due to the increased reactivity of heavier alkali metals and the considerable hazards involved with their synthesis. As well as CsHMDS, ${ }^{19}$ other donor-free structurally characterized cesium secondary amide compounds, including salts of (trimethylsilyl)-

Received: April 5, 2016 
(phenyldimethylsilyl)amide, ${ }^{20}$ bis(diphenylphosphanyl)amide, ${ }^{21}$ 1,1-bis(trimethylsilyl)-2-phenylhydrazide, ${ }^{22}$ carbazole, ${ }^{23}$ and $\mathrm{N}\left(\mathrm{C}_{6} \mathrm{~F}_{5}\right)\left\{\mathrm{C}\left(\mathrm{CF}_{3}\right)_{3}\right\}$, have been reported. ${ }^{24}$ To the best of our knowledge, only six cesium salts of the aforementioned utility amides have been structurally characterized. Five of these contain HMDS $^{19,25}$ and one contains TMP. ${ }^{26}$ Common protocols used to prepare heavy alkali metal amides include metathesis reactions of the corresponding lithium amide with heavier alkali metal alkoxides (i.e., $\mathrm{NR}_{2} \mathrm{Li}+$ $\mathrm{R}^{\prime} \mathrm{OM}$ system $)^{27}$ and deprotonation of the amine with metallic alkali metal, ${ }^{25 \mathrm{c}}$ alkali metal alkyl, aryl, hydride or alkoxide. ${ }^{20,21}$ However, these methods have issues as they involve expensive reagents, many of which have to be synthesized or are extremely hazardous to manipulate. One of the most extensively used reactions involving alkali metal amides is the amide transfer reaction when an alkali metal amide reacts with metal halides (Scheme 1). ${ }^{28}$

Scheme 1. Alkali Metal Amides As Amide Transfer Reagents in the Presence of Metal Halides

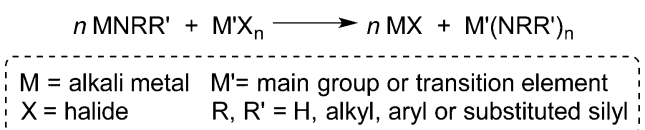

Salt metathesis using alkali metal halides is a common method employed for the synthesis of transition metals, ${ }^{29}$ lanthanides, ${ }^{30}$ and alkaline-earth metal amides. ${ }^{3,31}$ However, to the best of our knowledge, this methodology has not been used before for the synthesis of heavy alkali metal amides. Here, we present a standardized protocol to safely prepare pure CsHMDS, not involving the risks associated with using cesium metal or organocesium reagents, avoiding decomposition related processes (i.e., metalation of solvents, etc. employed in the reaction) by using a CsF-salt metathesis approach. Our next objective was to prepare a series of heterobimetallic alkali metal complexes containing CsHMDS. Mixed alkali metal complexes have been found to offer enhanced reactivity over monometallic ones. For instance, Wittig reported that a 1:1 phenylsodium/phenyllithium mixture provided enhanced reactivity in the nucleophilic addition reaction toward benzophenone compared to homometallic derivatives (no reaction with phenyllithium). ${ }^{32}$ Perhaps the most widely studied examples include the Lochmann-Schlosser superbase, which is a combination of $n$-butyllithium and potassium tert-butoxide (LiCKOR base). ${ }^{33}$ This synergic "LiCKOR" system is a powerful metalating agent used in synthetic chemistry for deprotonation of a wide range of substrates. ${ }^{34}$

O'Shea has increased the interest in these type of heteroleptic complexes through his LiNK superbase system $\left(\mathrm{LiTMP} / \mathrm{KO}^{t} \mathrm{Bu}\right)$ which provides a different selectivity in metalation reactions of substituted benzylic substrates with respect to the Lochmann-Schlosser superbase system. ${ }^{35}$ Since Williard's work in 1991, ${ }^{36}$ few studies have included structural information relating to the chemistry of homoleptic heteroalkali-metal utility amide species (these reagents can display enhanced deprotonative ability, ${ }^{37}$ as shown by other mixed alkali metal organic formulations). This paper details our study on mixed-alkali metal/HMDS complexes in the solid state and in solution, as well as our investigations on donor complexes of CsHMDS.

\section{RESULTS AND DISCUSSION}

Synthesis. The focus of this work was to provide structural insight into heteroalkali metal/HMDS compounds as well as donor aggregates of homometallic CsHMDS. A primary goal was to develop a safe and efficient method for the synthesis of the key reagent, CsHMDS, in particular, to negate the need for utilizing Cs metal.

CsHMDS 1 was synthesized by treating anhydrous cesium fluoride with a $n$-hexane solution of LiHMDS [itself prepared in $s i t u$ via deprotonation of $\operatorname{HMDS}(\mathrm{H})$ with $n$-BuLi] to undergo a salt metathesis reaction (Scheme 2). This implies a 1:1 metal

Scheme 2. Synthesis of Cesium Bis(trimethylsilyl)amide, Avoiding the Use of Cesium Metal

$$
\begin{aligned}
& \text { LiHMDS + CsF } \underset{\text { ii) }- \text { LiF, toluene }}{\stackrel{\text { i) } \Delta, n \text {-hexane }}{\longrightarrow}} \begin{array}{c}
\text { CsHMDS } \\
1(80 \%)
\end{array} \\
& \text { iii) sublimation }
\end{aligned}
$$

interchange reaction, i.e., CsHMDS and formation of LiF. A precipitate was obtained by refluxing the reaction mixture for $15 \mathrm{~h}$, and after removal of the solvent in-vacuo, toluene was added to the reaction mixture to dissolve the cesium amide ( $\mathrm{LiF}$ is insoluble in toluene). The reaction was filtered to yield a colorless solution. The final product $\mathbf{1}$ appeared as a white crystalline solid $^{25 c}$ in a good yield (80\%) after sublimation. The product is stable under inert argon atmosphere for several months.

Following our success in the preparation of CsHMDS using the cesium halide route, the material was then utilized in the preparation of mixed-alkali metal amide reagents. The combination of CsHMDS with lithium reagents was attempted first as the difference in size between the alkali metals helped to combat issues related to mutual substitution disorder, observed when similarly sized alkali metals are present within a structure. $^{38}$

The initial reaction involved a synthetic route similar to that for 1. A $n$-hexane solution of LiHMDS was reacted with cesium fluoride, this time in a 2:1 LiHMDS/CsF molar ratio for $8 \mathrm{~h}$ at $68{ }^{\circ} \mathrm{C}$. This synthetic route led to the preparation of a heterobimetallic lithium/cesium containing polymer [LiCs$\left.(\mathrm{HMDS})_{2}\right]_{\infty} 2$ in moderate yields from a $n$-hexane/toluene mixture (57\% yield based on the consumption of $\mathrm{CsF}$ ) (Scheme 3a).

Scheme 3. Syntheses of (a) $\left[\mathrm{LiCs}(\mathrm{HMDS})_{2}\right]_{\infty} 2$ and (b) $\left[\text { toluene } \cdot \mathrm{NaCs}(\mathrm{HMDS})_{2}\right]_{\infty} 3$
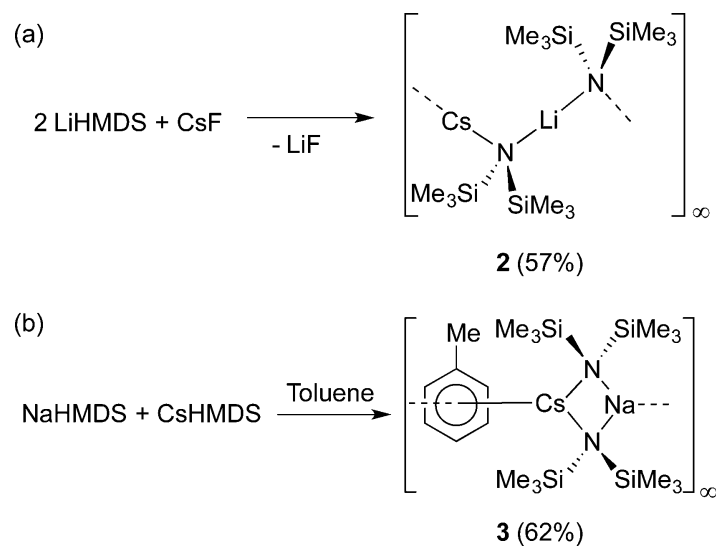


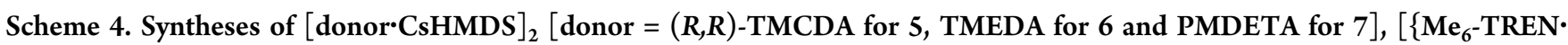
$\left.\mathrm{Cs}(\mathrm{HMDS})\}_{2}\{\mathrm{Cs}(\mathrm{HMDS})\}_{2}\right] 8$, and [TMEEA·CsHMDS $] 9$

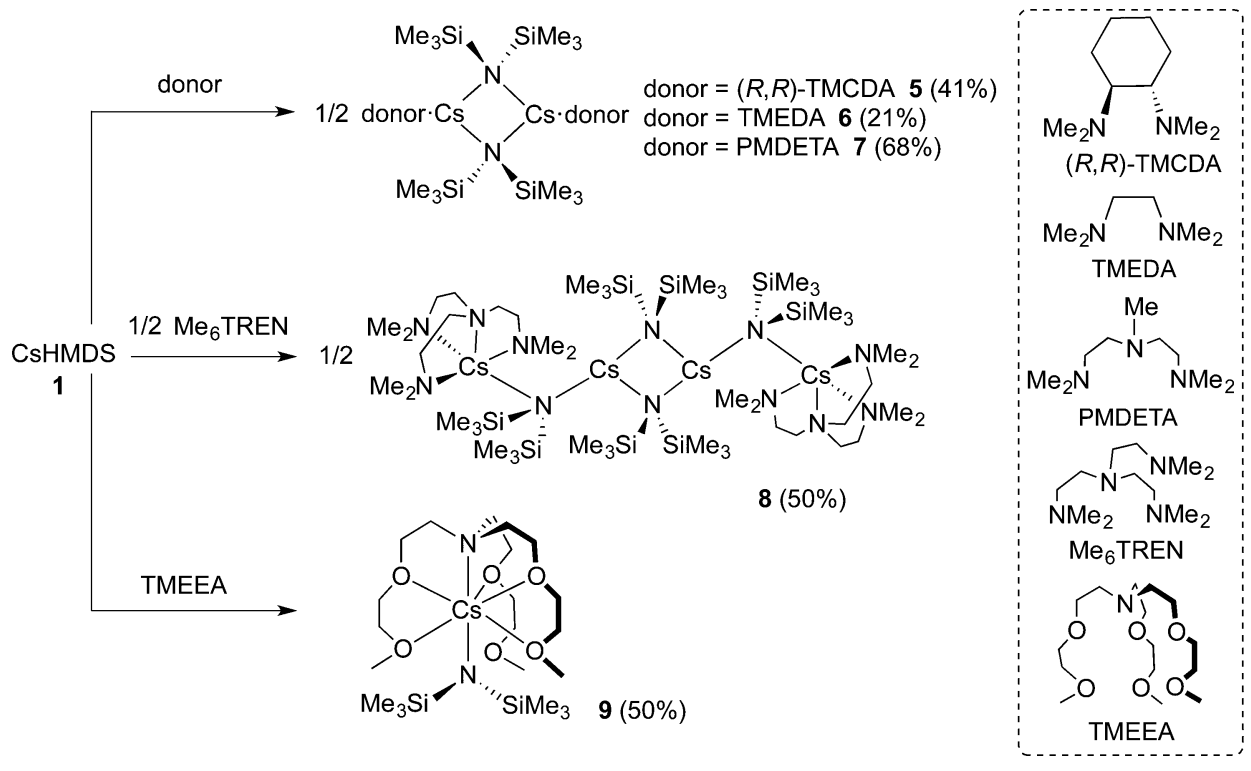

Because of the success of this reaction, it was decided to try to prepare a mixed-alkali metal aggregate containing sodium and cesium. A different synthetic approach was adopted and involved the combination of equimolar amounts of the homometallic reagents NaHMDS and CsHMDS in a hexane/ toluene mixture, allowing the isolation of the mixed sodiumcesium amide polymer [toluene $\left.\cdot \mathrm{NaCs}(\mathrm{HMDS})_{2}\right]_{\infty} 3$ (isolated yield, 62\%) (Scheme 3b).

Attempts to prepare a K/Cs hetero-bimetallic complex by reacting the monometallic amide species in a 1:1 ratio led to the preparation of an all cesium polymer [toluene. (CsHMDS $\left.)_{2}\right]_{\infty} 4$ previously reported in the literature. ${ }^{19}$

With the aim of providing additional structural insight in the aggregation behavior of CsHMDS (thus far only a discrete dimer and a few polymeric aggregates are reported in literature), ${ }^{19,25 b, c}$ the influence of the denticity of Lewis base donors on the formation of CsHMDS containing aggregates was studied. The initial donors selected were the bidentate ligands $(R, R)-N, N, N^{\prime}, N^{\prime}$-tetramethylcyclohexane-1,2-diamine $[(R, R)-\mathrm{TMCDA}]$ and $N, N, N^{\prime}, N^{\prime}$-tetramethylethylenediamine (TMEDA). By combining CsHMDS and the corresponding bidentate donor in a 1:1 stoichiometric ratio in hexane, two dimers $[\text { donor } \cdot \mathrm{CsHMDS}]_{2}[$ donor $=(R, R)-\mathrm{TMCDA}$ for $\mathbf{5}$ and TMEDA for 6 in $41 \%$ and $21 \%$ crystalline yields, respectively] were synthesized from respective $n$-hexane solutions (Scheme 4). These yields were not optimized, and $\mathbf{5}$ and $\mathbf{6}$ were highly soluble in $n$-hexane.

Interestingly, when an $n$-hexane/toluene mixture of solvents was used for the synthesis of $\mathbf{6}$, the toluene solvate, 4 was isolated. This provides experimental evidence that heavier alkali metals favor softer metal- $\pi$ interactions with arenes rather than dative bonding to harder amino ligands.

When the bidentate ligand is substituted for the tridentate $\mathrm{N}$ donor $N, N, N^{\prime}, N^{\prime \prime}, N^{\prime \prime}$-pentamethyldiethylenetriamine (PMDETA) (Scheme 4), a complex with a dimeric motif similar to that of 5 and 6, [PMDETA.CsHMDS $]_{2} 7$ (68\%), was obtained (Scheme 4). Compound 7 was first isolated from the reaction of $\left[\mathrm{LiCs}(\mathrm{HMDS})_{2}\right]_{\infty} \mathbf{2}$ in $n$-hexane with PMDETA in a 1:2 stoichiometric ratio. Nichols et al. reported NMR spectroscopic experiments involving a mixture of LiHMDS and KHMDS in a 1:1 stoichiometric ratio with addition of TMEDA. These results showed monomeric [TMEDA.LiHMDS] and dimeric $[\mathrm{TMEDA} \cdot \mathrm{KHMDS}]_{2}$ species were present, interestingly with no NMR spectroscopic evidence for formation of mixed alkali metal HMDS aggregates in the presence of only TMEDA. ${ }^{39}$

The reaction combining the tetradentate ligand tris[2(dimethylamino)ethyl] amine ( $\left.\mathrm{Me}_{6} \mathrm{TREN}\right)$ and CsHMDS initially in a 1:1 ratio yielded the tetranuclear aggregate $\left[\left\{\mathrm{Me}_{6}-\mathrm{TREN} \cdot \mathrm{Cs}(\mathrm{HMDS})\right\}_{2}\{\mathrm{Cs}(\mathrm{HMDS})\}_{2}\right]$ 8. Similar moieties have been reported for $\mathrm{KR}$ compounds $[\mathrm{R}=\mathrm{CH}$ $\left.\left(\mathrm{SiMe}_{3}\right)_{2}\right]{ }^{40}$ but as far as we are aware, this is the first in Cs amide chemistry. In an attempt to optimize the reaction conditions, the stoichiometry of the reaction was adjusted to 2:1 CsHMDS: $\mathrm{Me}_{6} \mathrm{TREN}$, and $\mathbf{8}$ was isolated in a moderate crystalline yield of $50 \%$ (Scheme 4).

In our attempt to expand the scope of the reaction to smaller (and by implication more reactive) aggregates, a $n$-hexane suspension of CsHMDS was reacted with the strong chelating heptadentate tris[2-(2-methoxyethoxy)ethyl]amine (TMEEA) producing a dark brown oil. After addition of toluene, a brown solution was obtained which was stored at $-33{ }^{\circ} \mathrm{C}$ to produce crystals of the monomeric species [TMEEA.CsHMDS] 9 (49\%) (Scheme 4).

X-ray Diffraction Studies. Compounds 2, 3, and 5-9 were successfully prepared and characterized in the solid state by Xray diffraction studies (full details are given in Tables $S 2$ and S3). Crystals of $\mathbf{2}$ and $\mathbf{3}$ were obtained from cocomplexation reactions of the homometallic amides in solution, while 5-9 were obtained from the appropriate CsHMDS/donor solution as detailed in the Experimental Section. All the reactions were optimized for the production of high quality crystals suitable for $\mathrm{X}$-ray diffraction studies.

Complexes 2 and 3 consist of an early ( $\mathrm{Li}$ or $\mathrm{Na}$, respectively) and heavy alkali metal Cs bis(trimethylsilyl)amide (HMDS) unit building polymeric assemblies. However, distinct polymeric arrays are obtained depending on the size of the lighter alkali metal cation. To the best of our knowledge, $\left[\mathrm{LiCs}(\mathrm{HMDS})_{2}\right]_{\infty} 2$ represents the second example of an 


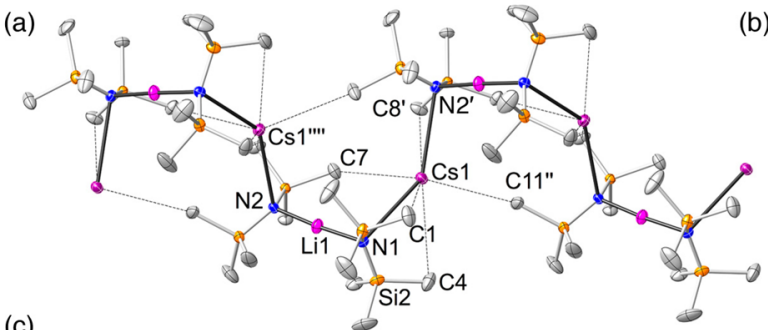

(b)

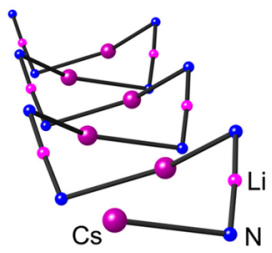

(c)

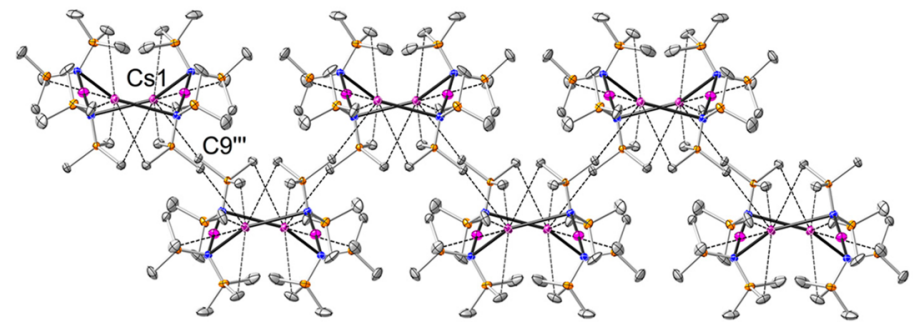

Figure 1. (a) Molecular structure of $\left[\mathrm{LiCs}(\mathrm{HMDS})_{2}\right]_{\infty} 2$ showing a section of the polymeric chain. Hydrogen atoms and one component of a disordered $\mathrm{SiMe}_{3}$ groups are omitted for clarity. The displacement ellipsoids are displayed at $35 \%$ probability. (b) Ball and stick representation in perspective mode along the crystallographic $b$-axis showing the $\mathrm{Cs}-\mathrm{N}-\mathrm{Li}-\mathrm{N}$ wave-like chain arrangement where the $\mathrm{SiMe}_{3}$ groups have been omitted for clarity. (c) Section of the packing diagram showing the zigzag array between polymeric chains in the crystallographic a,c-plane. The dashed lines illustrate Cs $\cdots M e$ agostic interactions. Selected bond distances $(\AA)$ and angles (deg): $\mathrm{Cs}(1)-\mathrm{N}(1) 3.289(3), \mathrm{Cs}(1)-\mathrm{N}(2)^{\prime} 3.345(2)$, $\mathrm{Cs}(1)-\mathrm{C}(1)$ 3.623(4), $\mathrm{Cs}(1)-\mathrm{C}(3)^{\prime}$ 3.879(5), Cs(1)-C(8)' 3.759(4), Cs(1)-C(4) 3.761(5), Cs(1)-C(7) 3.739(4), Li(1)-N(1) 1.919(6), $\mathrm{Li}(1)-\mathrm{N}(2)$ 1.921(6), $\mathrm{Cs}(1)-\mathrm{C}(9)^{\prime \prime \prime} \quad 3.823(3) ; \mathrm{N}(1)-\mathrm{Li}(1)-\mathrm{N}(2)$ 175.7(4), $\mathrm{Li}(1)-\mathrm{N}(1)-\mathrm{Cs}(1) 102.8(2), \mathrm{N}(1)-\mathrm{Cs}(1)-\mathrm{N}(2)^{\prime} 141.30(6)$, $\mathrm{Li}(1)-\mathrm{N}(2)-\mathrm{Cs}(1)^{\prime \prime \prime \prime} 100.9(2)$. The symmetry operation used to generate the equivalent atoms labeled with ', ", '"' and '"'!' are $3 / 2-x, 1 / 2+y, z, x$, $y+1, z, 1-x,-y,-z$ and $3 / 2-x, y-1 / 2, z$, respectively.

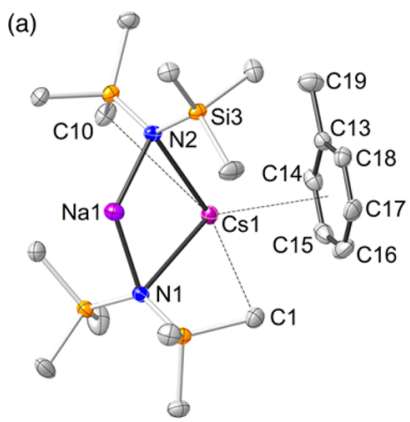

(b)

(c)

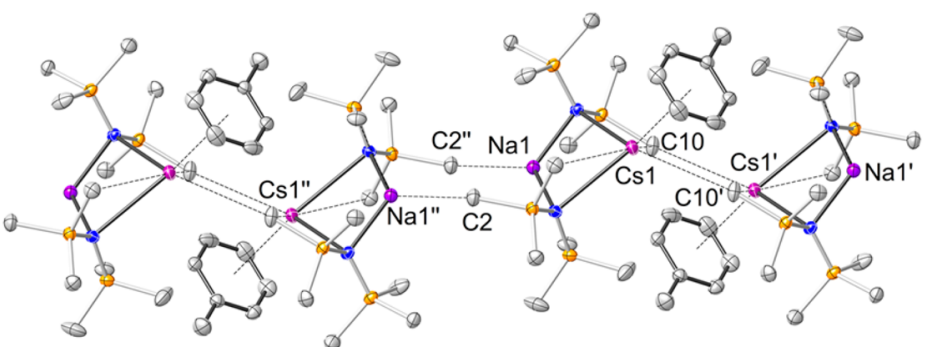

Figure 2. (a) Molecular structure of [toluene- $\left.\mathrm{NaCs}(\mathrm{HMDS})_{2}\right]_{\infty} 3$ showing the contents of the asymmetric unit which corresponds to a $[$ toluene$\mathrm{NaCs}(\mathrm{HMDS})_{2}$ ] unit. Hydrogen atoms are omitted for simplicity and displacement ellipsoids are displayed at $35 \%$ probability. (b) Section of the polymeric chain showing the $\mathrm{Na} \cdots \mathrm{Me}$ between dimeric [toluene $\cdot \mathrm{NaCs}(\mathrm{HMDS})_{2}$ ] units. (c) Section of the polymeric chain showing the Cs $\cdots$ Me interactions. Selected bond distances $(\AA)$ and angles (deg): $\mathrm{Na}(1)-\mathrm{N}(1) 2.362(3), \mathrm{Na}(1)-\mathrm{N}(2) 2.336(4), \mathrm{Cs}(1)-\mathrm{N}(1) 3.152(3), \mathrm{Cs}(1)-\mathrm{N}(2)$ 3.121(3), Cs(1)-C(1) 3.641(4), Cs(1)-C(10) 3.700(4), Na(1)-C(2)" 2.871(4), C(2)-Na(1)" 2.871(4), C(10)-Cs(1)' 3.691(4), Cs(1)$\mathrm{C}(10)^{\prime}$ 3.691(4); $\mathrm{Na}(1)-\mathrm{N}(1)-\mathrm{Cs}(1)$ 80.46(9), $\mathrm{Na}(1)-\mathrm{N}(2)-\mathrm{Cs}(1)$ 81.50(10), N(2)-Na(1)-N(1) 118.09(12), N(2)-Cs(1)-N(1) 79.92(8). The symmetry operation used to generate the equivalent atoms labeled with ' and " are $1-x, 2-y, 2-z$ and $-x, 1-y, 1-z$, respectively.

unsolvated lithium-containing mixed-alkali metal HMDS species; only the unsolvated $\left[\mathrm{LiK}(\mathrm{HMDS})_{2}\right]$ is known. ${ }^{41}$ Complex 2 adopts a wave-like polymeric chain arrangement composed of alternating $\left[\mathrm{LiCs}(\mathrm{HMDS})_{2}\right]$ units along the crystallographic $b$-axis (Figure $1 \mathrm{a}, \mathrm{b}$ ). Mirroring [LiK$\left.(\mathrm{HMDS})_{2}\right]$, the $\left[\mathrm{LiCs}(\mathrm{HMDS})_{2}\right]$ units adopt a notable open $[\mathrm{Li}-\mathrm{N}-\mathrm{Cs}-\mathrm{N}]$ array. This "open" dimeric arrangement is a distinctive structural feature when comparing with other related heteroalkali metal HMDS amides salts which normally adopt a $\left[\mathrm{M}\left(\mu-\mathrm{N}_{2}\right) \mathrm{M}^{\prime}\right]$ heterodimeric ring in the presence of THF as a donor molecule. ${ }^{36}$

The asymmetric unit contains $\mathrm{Cs}$ and $\mathrm{Li}$ cations and two bridging HMDS anions that link the metals through the $\mathrm{N}$ atoms, allowing the aforementioned propagation along the 

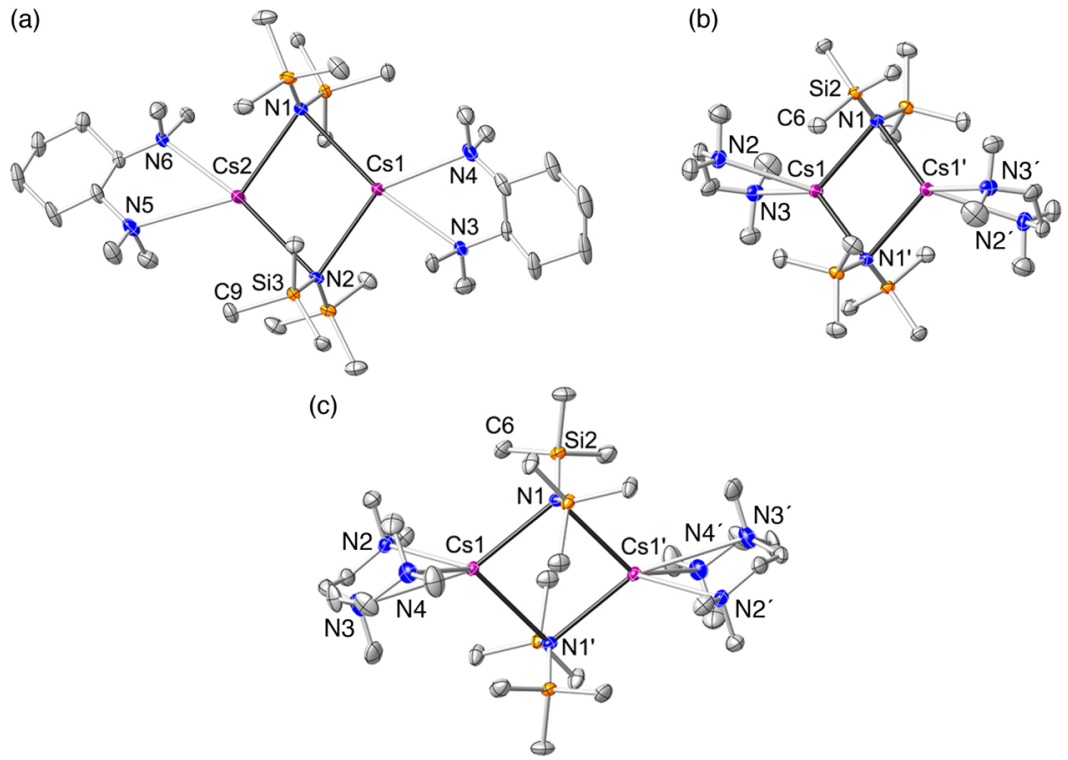

Figure 3. (a) Molecular structure of $[(R, R)-T M C D A \cdot C s H M D S]_{2}$ 5, (b) [TMEDA.CsHMDS $]_{2} 6$ and (c) [PMDETA.CsHMDS $]_{2}$ 7. Hydrogen atoms, and one disordered component of the (R,R)-TMCDA, TMEDA and PMDETA ligands in 5, 6, and 7, respectively, are omitted for clarity. Displacement ellipsoids are displayed at $35 \%$ probability. Selected bond distances $(\AA)$ and angles (deg) for 5: Cs(1) $-\mathrm{N}(1) 3.310(3)$, Cs $(1)-\mathrm{N}(2)$ 3.112(3), Cs(1)-N(3) 3.172(4), Cs(2)-N(1) 3.123(3), Cs(2) $-\mathrm{N}(2)$ 3.325(3), Cs(2)-N(5) 3.302(4), Cs(2) $-\mathrm{N}(6) 3.242(4) ; \operatorname{Cs}(1)-\mathrm{N}(2)-$ $\mathrm{Cs}(2)$ 80.80(7), $\mathrm{Cs}(2)-\mathrm{N}(1)-\mathrm{Cs}(1)$ 80.89(8), N(3)-Cs(1) $-\mathrm{N}(4)$ 51.51(18), $\mathrm{N}(6)-\mathrm{Cs}(2)-\mathrm{N}(5)$ 52.02(9); for 6: Cs(1) $-\mathrm{N}(1)$ 3.0551(18), $\mathrm{Cs}(1)-\mathrm{N}(1)^{\prime}$ 3.1920(18), Cs(1)-N(2) 3.288(2), Cs(1)-N(3) 3.183(2), Cs(1)-C(1)' 3.679(3); Cs(1)-N(1)-Cs(1)' 86.26(4), N(1)-Cs(1)$\mathrm{N}(1)^{\prime}$ 93.74(4), $\mathrm{N}(3)-\mathrm{Cs}(1)-\mathrm{N}(2)$ 56.41(6); and for 7: Cs(1)-N(1) 3.2134(16), Cs(1)-N(1)' 3.1637(17), Cs(1)-N(2) 3.3316(19), Cs(1)$\mathrm{N}(3) 3.4229(19), \mathrm{Cs}(1)-\mathrm{N}(4)$ 3.3010(18); N(1)'-Cs(1)-N(1) 86.43(4), Cs(1)'-N(1)-Cs(1) 93.57(4); N(4) $-\mathrm{Cs}(1)-\mathrm{N}(2) 96.37(5), \mathrm{N}(4)-$ $\mathrm{Cs}(1)-\mathrm{N}(3) 52.68(5), \mathrm{N}(2)-\mathrm{Cs}(1)-\mathrm{N}(3) 53.54(5)$. The symmetry operation used to generate the equivalent atoms labeled with ' in 6 and 7 are $1 / 2-x, 1 / 2-y, 1-z$ and $1-x, 1-y, 1-z$, respectively.

crystallographic $b$ axis. While the $\mathrm{N}-\mathrm{Li}-\mathrm{N}$ angle is close to linearity $\left[175.7(4)^{\circ}\right]$, the $\mathrm{N}-\mathrm{Cs}-\mathrm{N}$ angle is narrower $\left[141.30(6)^{\circ}\right]$. Each $\mathrm{Li}$ and $\mathrm{Cs}$ cation thus presents a formal coordination number of two with respect to $\mathrm{N}_{\text {amido }}$ ions. However, in addition each Cs cation exhibits seven long Cs... $\mathrm{Me}$ agostic-type interactions [Cs $\cdots \mathrm{C}$ range 3.623(4)-3.879(5) $\AA]$ with neighboring $\mathrm{SiMe}_{3}$ groups. These both help to support the growth of the chain and interconnect neighboring chains. Significant structural modifications are noted when the larger alkali metal $\mathrm{Na}$ is introduced in place of the $\mathrm{Li}$ cations. In contrast to the open chain like $[\mathrm{Li}-\mathrm{N}-\mathrm{Cs}-\mathrm{N}]$ motif observed in 2 , the structure of [toluene $\left.\cdot \mathrm{NaCs}(\mathrm{HMDS})_{2}\right]_{\infty} \quad 3$ is comprised of solvated four-membered $[\mathrm{Na}-\mathrm{N}-\mathrm{Cs}-\mathrm{N}]$ cyclodimeric units as commonly observed in other hetero bialkali metal HMDS species. ${ }^{36}$ The HMDS ligands asymmetrically bridge $\mathrm{Na}$ to $\mathrm{Cs}$, with $\mathrm{Na}-\mathrm{N}$ bond lengths of 2.336(4) and 2.362(3) $\AA$ and $\mathrm{Cs}-\mathrm{N}$ bond lengths of 3.121(3) and 3.152(3) $\AA$. This situation leaves the larger Cs metal center coordinatively unsaturated, thus allowing the coordination of one molecule of toluene via $\pi$-arene bonding interactions [Cs... arene(centroid), $3.339 \AA]$ and three close Cs $\cdots$ Me contacts [Cs $\cdots C$ range $3.641(4)-3.700(4) \AA]$. This type of $\eta^{6}$-bonding of an arene is a common feature found in alkali metal organometallic complexes. ${ }^{42}$ There are also short $\mathrm{Na} \cdots \mathrm{Me}$ contacts, and the $\mathrm{Na} \cdots \mathrm{C} 2$ contacts $[2.871(4) \AA]$ connect the [toluene $\cdot \mathrm{NaCs}(\mathrm{HMDS})_{2}$ ] units into pairs, and Cs $\cdots \mathrm{Me}$ contacts then connect these dimeric $\mathrm{Na} / \mathrm{Cs}$ units and so allow the growth of $\mathbf{3}$ as a polymeric chain in the solid state (Figure 2).

Compounds 5, 6, and 7 all crystallize in the monoclinic crystallographic system and consist of planar four-membered homometallic [Cs-N-Cs-N] (N from HMDS) cyclo-dimers with a bidentate $[(R, R)$-TMCDA for 5 and TMEDA 6] or tridentate (PMDETA for 7) $\mathrm{N}$ donor ligand terminally coordinated to each Cs atom (Figure 3). Two sets of shorter and longer $\mathrm{Cs}-\mathrm{N}$ bond lengths are found in the $\mathrm{Cs}_{2} \mathrm{~N}_{2}$ rings for 5-7 [short: Cs1-N2 and Cs2-N1 bond lengths of 3.112(3) and 3.123(3) $\AA$, respectively, for 5, Cs1-N1 of 3.0551(18) $\AA$ for 6 and Cs1-N1 of 3.1637(17) $\AA$ for 7; long: Cs1-N1 and Cs2-N2 bond lengths of $3.310(3)$ and $3.325(3) \AA$, respectively, for $5, \mathrm{Cs}^{-}-\mathrm{N1}^{\prime}$ of $3.1920(18)$ for 6 and 3.2134(16) for 7, Figure 3]. A similar trend is observed for the $\mathrm{N}_{\text {donor }}$ to the Cs metal center when the donor molecule is $(R, R)$-TMCDA or TMEDA for 5 and 6, respectively [short: Cs1-N3 and Cs2-N6 bond lengths of 3.172(4) and 3.242(4) for 5, and Cs1-N3 of 3.183(2) for 6; long: Cs2-N5 bond length of 3.302(4) for 5, and Cs1-N2 of 3.288(2) A for 6, Figure 3]. For 7 , the $\mathrm{N}_{\text {donor }}-\mathrm{Cs}$ bond lengths are 3.3010(18) and 3.3316(19) $\AA$ with the two lateral N4 and N2 atoms from the PMDETA ligand, respectively, whereas it is longer with the central N3 atom [3.4229(19) $\AA$ ]. This variance in the Cs-N bond lengths can be explained by the presence of $\mathrm{N}_{\text {anionic }}$ and $\mathrm{N}_{\text {dative }}$ interactions with the Cs metal cations. Note that although 5 and $\mathbf{6}$ both have bidentate donor ligands, these are orientated differently with TMEDA lying approximately perpendicular to the $[\mathrm{Cs}-\mathrm{N}-\mathrm{Cs}-\mathrm{N}]$ ring in $\mathbf{6}$ but $(R, R)$ TMCDA oriented roughly coplanar with $[\mathrm{Cs}-\mathrm{N}-\mathrm{Cs}-\mathrm{N}]$ in $\mathbf{5}$. The Cs $-\mathrm{N}_{\text {amido }}-\mathrm{Cs}$ bond angles in 5, 6, and 7 depend on the nature of the donor ligand, which is coordinated to the Cs cation. An increase in the Cs-N-Cs angle is observed when moving from bidentate $(R, R)$-TMCDA and TMEDA [Cs1$\mathrm{N} 1-\mathrm{Cs} 2$ and Cs1-N2-Cs2 angles of $80.89(8)$ and 80.80(7), respectively, for 5; and $\mathrm{Cs1}-\mathrm{N1}-\mathrm{Cs}^{\prime}{ }^{\prime}$ angle of $86.26(4)^{\circ}$ for 6] to the tridentate $\mathrm{N}$ ligand PMDETA (mean Cs-N-Cs 
angle, $93.6^{\circ}$ for 7 ). Looking at the unsolvated congener $[\mathrm{CsHMDS}]_{2}{ }^{19}$ a decrease in the Cs-N-Cs angle (mean Cs$\mathrm{N}-\mathrm{Cs}$ angle, $89.6^{\circ}$ ) is observed compared to 7 . The intermetallic Cs $\cdots$ Cs distance in the dimeric species 5-7 and $[\mathrm{CsHMDS}]_{2}$ also reflects the same trend observed for the Cs$\mathrm{N}-\mathrm{Cs}$ angle [Cs...Cs distance increase in the series 5 $[4.1752(3) \AA]<6[4.2719(3) \AA]<[\text { CsHMDS }]_{2}[4.4153(3)$ $\AA]^{19}<7[4.6476(3) \AA]$. The solid state structure of 6 can be compared and contrasted with the previously published organocesium polymer [TMEDA. Cs $\left.\left\{\mu-\mathrm{CH}\left(\mathrm{SiMe}_{3}\right)_{2}\right\}\right]_{\infty}$ (Figure 4). ${ }^{40}$ This complex exhibits a polymeric structure of alternating "open dimeric" [Cs-C-Cs-C] units in contrast to the discrete dimeric $\left[\mathrm{Cs}_{2} \mathrm{~N}_{2}\right]$ units found in $\mathbf{6}$.

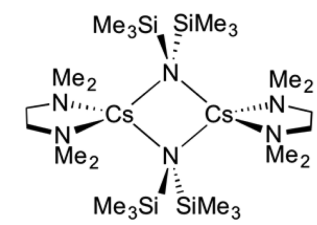

[TMEDA.CsHMDS] $]_{2}(6)$

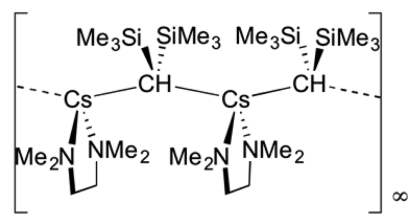

[TMEDA. $\left.\mathrm{Cs}\left\{\mu-\mathrm{CH}\left(\mathrm{SiMe}_{3}\right)_{2}\right\}\right]_{\infty}$
Figure 4. Structural formulas of [TMEDA.CsHMDS $]_{2} \quad \mathbf{6}$ and $\left[\mathrm{TMEDA} \cdot \mathrm{Cs}\left\{\mu-\mathrm{CH}\left(\mathrm{SiMe}_{3}\right)_{2}\right\}\right]_{\infty}$.

When the bulky $\mathrm{N}$ tetradentate $\mathrm{Me}_{6}$ TREN donor molecule is employed, the product has two distinct Cs environments and forms $\left[\left(\mathrm{Me}_{6} \mathrm{TREN} \cdot \mathrm{CsHMDS}\right)_{2}(\mathrm{CsHMDS})_{2}\right] \mathbf{8}$ (Figure 5). Complex 8 can be considered as two dimeric [\{ $\mathrm{Me}_{6} \mathrm{TREN}$. $\mathrm{Cs}\}-\mathrm{N}-\mathrm{Cs}-\mathrm{N}]$ chains which combine, via a central planar

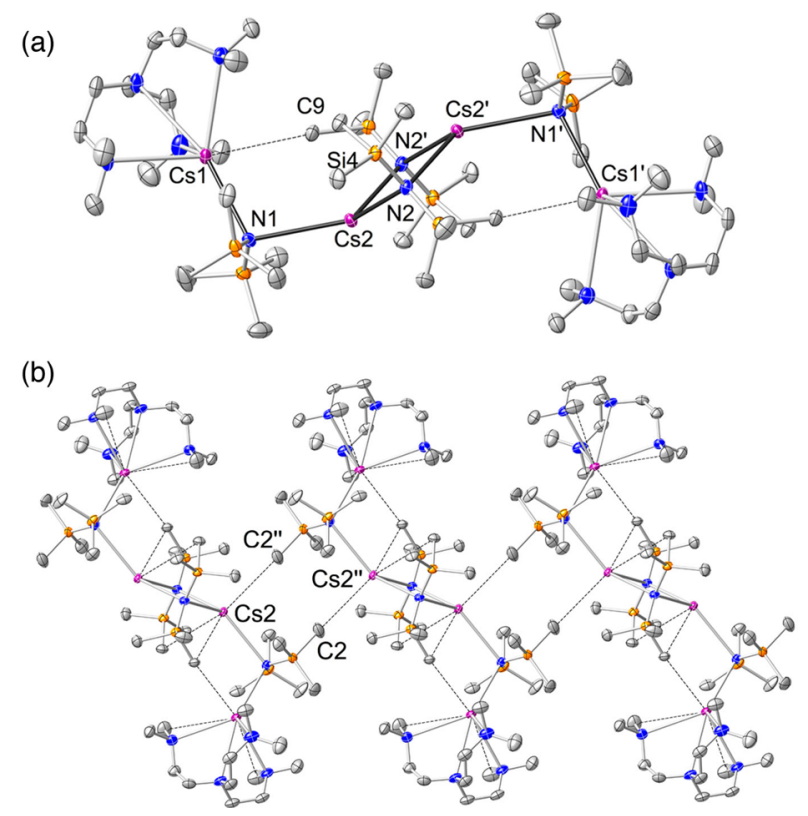

Figure 5. (a) Molecular structure of $\left[\left\{\mathrm{Me}_{6}-\mathrm{TREN} \cdot \mathrm{Cs}(\mathrm{HMDS})\right\}_{2}\{\mathrm{Cs}-\right.$ (HMDS $\left.)\}_{2}\right]$ 8. Hydrogen atoms and one disordered toluene molecule of crystallization are omitted for simplicity. Displacement ellipsoids are displayed at $35 \%$ probability. (b) Section of the polymeric arrangement showing the intermolecular Cs $\cdots$ Me interactions. Selected bond distances $(\AA)$ and angles (deg): $\mathrm{Cs}(1)-\mathrm{N}(1) 3.129(2), \mathrm{Cs}(2)-\mathrm{N}(2)$ 3.149(2), $\mathrm{Cs}(2)-\mathrm{N}(2)^{\prime} \quad 3.168\left(2, \mathrm{Cs}(2)-\mathrm{C}(2)^{\prime \prime} \quad 3.687(4) ; \mathrm{Cs}(1)-\right.$ $\mathrm{N}(1)-\mathrm{Cs}(2)$ 106.00(6), $\mathrm{N}(2)-\mathrm{Cs}(2)-\mathrm{N}(2)^{\prime}$ 92.85(5). The symmetry operation used to generate the equivalent atoms labeled with ' and " are $1-x, 1-y,-z$ and $-x, 1-y,-z$, respectively. cyclo-dimer $[\mathrm{CsHMDS}]_{2}$ unit. As the molecule is crystallographically centrosymmetric, the $\mathrm{Me}_{6}$ TREN units are mutually anti with respect to the $[\mathrm{CsNCsN}]$ ring plane. The Cs cations in this central dimer adopt a distorted trigonal pyramidal geometry [N2-Cs2-N2', 92.85(5); N2-Cs2-N 1 , $128.29(5)^{\circ}$; and $\left.\mathrm{N} 2^{\prime}-\mathrm{Cs} 2-\mathrm{N} 1,125.72(5)^{\circ}\right]$. The $\mathrm{Me}_{6}$ TREN ligands coordinate to the outer $\mathrm{Cs}$ atoms in an $\eta^{4}$-fashion, rendering these five-coordinate. The three $\mathrm{N}$-donor arms emerging from the central $\mathrm{N}$ donor in $\mathrm{Me}_{6}$ TREN are disposed in a plane whereby the cesium atom deviates by $1.69 \AA$. Neighboring $\left[\left\{\mathrm{Me}_{6}-\mathrm{TREN} \cdot \mathrm{Cs}(\mathrm{HMDS})\right\}_{2}\{\mathrm{Cs}(\mathrm{HMDS})\}_{2}\right]$ units are linked by intermolecular Cs..Me interactions (Figure 5).

The structural motif of $\mathbf{8}$ is similar to that in the organopotassium compound $\left[(\mathrm{PMDETA} \cdot \mathrm{KR})_{2}(\mathrm{KR})_{2}\right]$ complex (where $\left.\mathrm{R}=\mu-\mathrm{CH}\left(\mathrm{SiMe}_{3}\right)_{2}\right)$. ${ }^{40} \mathrm{~A}$ search of the Cambridge Crystallographic Database ${ }^{23 \mathrm{~b}, 43}$ reveals that $\mathbf{8}$ is the first structurally characterized example of a complex where $\mathrm{Me}_{6}$ TREN coordinates to a Cs atom.

When 1 equiv of CsHMDS reacts with stoichiometric amounts of the heptadentate $\mathrm{N}_{6} \mathrm{O}$ ligand TMEEA, the donor ligand chelates a single $\mathrm{Cs}$ atom through all of its heteroatoms, stabilizing and constructing a sterically protected, discrete monomeric CsHMDS complex [TMEEA.CsHMDS] 9 (Figure 7). The coordination number of Cs is eight. Compound 9 is a rare example of a mononuclear cesium amide species, only the structure of the monometallic [(18-crown-6) $\left.\cdot \mathrm{Cs}\left\{\mathrm{N}\left(\mathrm{PPh}_{2}\right)_{2}\right\}\right]$ has been previously reported. ${ }^{21}$ Looking at the $\mathrm{Cs}-\mathrm{N}$ bond lengths, two distinct distances are observed in the solid state of 9, the shorter 3.0856(17) $\AA$ corresponds to a Cs-N $\sigma$ interaction with the amide HMDS ligand, and the longer 3.3189(15) A corresponds to a Cs-N lone-pair dative interaction established between the Cs metal center and the $\mathrm{N}$ atom of the heptadentate TMEEA ligand.

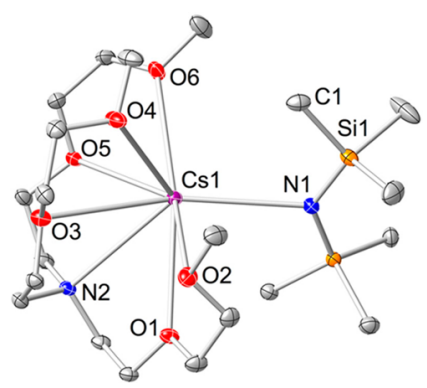

Figure 6. Molecular structure of [TMEEA.CsHMDS] 9. Hydrogen atoms are omitted for simplicity. Displacement ellipsoids are displayed at $35 \%$ probability. $\mathrm{Cs}(1)-\mathrm{N}(1) 3.0856(17), \quad \mathrm{Cs}(1)-\mathrm{N}(2)$ 3.3189(15), Cs(1)-O(1) 3.1250(12), Cs(1)-O(2) 3.3554(14), $\mathrm{Cs}(1)-\mathrm{O}(3) \quad 3.2941(14), \mathrm{Cs}(1)-\mathrm{O}(4)$ 3.0911(13), Cs(1)-O(5) 3.1880(13), Cs(1)-O(6) 3.1520(13); N(1)-Cs(1)-N(2) 131.42(4).

NMR Spectroscopic Studies. Compounds 1-9 were completely characterized by ${ }^{1} \mathrm{H},{ }^{13} \mathrm{C}$, and ${ }^{133} \mathrm{Cs}$ NMR spectroscopies in deuterated arene solvents $\left(\mathrm{C}_{6} \mathrm{D}_{6}\right.$ and toluene- $\left.d_{8}\right)$. Resonances observed in ${ }^{1} \mathrm{H}$ and ${ }^{13} \mathrm{C}$ NMR spectra are restricted to two distinct regions, corresponding to (i) the Lewis base donor of choice; and, (ii) the HMDS group. The Lewis donor ligand/HMDS ratio found in the ${ }^{1} \mathrm{H}$ NMR spectra are $1: 1$ for 5-7 and 9, while it is $1: 2$ for $\mathbf{8}$, in agreement with the proportions expected form the solid state structures.

The ${ }^{1} \mathrm{H}$ and ${ }^{13} \mathrm{C}$ NMR spectra of compound 1 in $\mathrm{C}_{6} \mathrm{D}_{6}$ consist of a single resonance at 0.21 and $7.3 \mathrm{ppm}$, respectively, corresponding to the $\mathrm{SiMe}_{3}$ group. ${ }^{25 \mathrm{c}}$ For the heterobimetallic 
complexes 2 and 3, singlets are observed in the ${ }^{1} \mathrm{H}$ NMR spectra in $\mathrm{C}_{6} \mathrm{D}_{6}$ at 0.27 and $0.28 \mathrm{ppm}$ (6.7 and $7.3 \mathrm{ppm}$ in the ${ }^{13} \mathrm{C}$ NMR spectra), respectively, which are slightly shifted downfield with respect to those of the corresponding monometallic reagents (i.e., 0.13/5.0 for LiHMDS, 0.12/6.9 for NaHMDS and 0.21/7.3 ppm for CsHMDS in the ${ }^{1} \mathrm{H} /{ }^{13} \mathrm{C}$ spectra). In this context, Williard et al. reported NMR spectroscopic studies which proposed the presence of a mixed-alkali metal HMDS dimeric aggregate $\left[(\mathrm{THF})_{3} \cdot \mathrm{LiK}\right.$ $\left.(\mathrm{HMDS})_{2}\right]_{2}$ in toluene- $d_{8}$ solution. ${ }^{39}$

In order to get more information on the aggregation states of 2 and 3 in arene solutions, a crystalline sample of each complex was treated with toluene- $d_{8}$ and studied by ${ }^{1} \mathrm{H}$ DOSY NMR spectroscopy ${ }^{44}$ at $300 \mathrm{~K}$ (see Supporting Information for full details). The diffusion coefficients obtained from these studies suggest an intermediate molecular weight between the respective toluene- $d_{8}$ solvated heteroalkali metal dimeric species $\left[\left(\text { toluene- } d_{8}\right)_{n} \cdot \mathrm{LiCs}(\mathrm{HMDS})_{2}\right]$ and $\left[\left(\text { toluene- } d_{8}\right)_{n} \cdot \mathrm{NaCs}-\right.$ $\left.(\mathrm{HMDS})_{2}\right]$ and the corresponding monometallic reagents [i.e., $\left[\left(\text { toluene- } d_{8}\right)_{n} \cdot \mathrm{LiHMDS}\right]_{n},\left[\left(\text { toluene- } d_{8}\right)_{n} \cdot \mathrm{NaHMDS}\right]_{n}$ and $\left.\left[\left(\text { toluene- } d_{8}\right)_{n} \cdot \text { CsHMDS }\right]_{n}\right]$ in the same solvent. This trend reflects partial deaggregation of 2 and 3 in toluene- $d_{8}$ solution producing the corresponding monometallic species, which through fast equilibria would exchange their HMDS ligands at $300 \mathrm{~K}$. A variable temperature ${ }^{1} \mathrm{H}$ NMR spectroscopic study of 2 in toluene- $d_{8}$ solution shows that this dynamic equilibrium still exists at $193 \mathrm{~K}$ (a single resonance at $0.41 \mathrm{ppm}$ is observed for the HMDS ligand at $193 \mathrm{~K}$; see Supporting Information).

Focusing on the dimeric species 5-7, the amido region in the ${ }^{1} \mathrm{H}$ NMR spectra obtained from $\mathrm{C}_{6} \mathrm{D}_{6}$ solutions at $300 \mathrm{~K}$ consist of a single resonance corresponding to the $\mathrm{SiMe}_{3}$ group (0.25, 0.23, and $0.27 \mathrm{ppm}$ for 5-7, respectively) which appears close to that of free CsHMDS in the same solvent $(0.21 \mathrm{ppm})$. Looking at the Lewis donor ligand region in each ${ }^{1} \mathrm{H}$ and ${ }^{13} \mathrm{C}$ spectra, the chemical shifts of the resonances are close to that of the corresponding noncoordinated donor molecules in the same solvent (Table S1). In agreement with these results, a ${ }^{1} \mathrm{H}$ DOSY NMR spectroscopic study of $\mathbf{6}$ (as a case of study) in toluene- $d_{8}$ at $300 \mathrm{~K}$ shows distinct values for the diffusion coefficients corresponding to HMDS and TMEDA ligands $\left(9.583 \times 10^{-10}\right.$ and $1.805 \times 10^{-9} \mathrm{~m}^{2} \mathrm{~s}^{-1}$, respectively), which in addition are distinct from those expected for $\mathbf{6}$, and for the values of CsHMDS or TMEDA in toluene- $d_{8}$ solutions (8.764 $\times 10^{-10}$ for CsHMDS and $2.00 \times 10^{-9} \mathrm{~m}^{2} \mathrm{~s}^{-1}$ for TMEDA, Figure S43). This data would indicate that a fast coordination/ decoordination process involving TMEDA and toluene- $d_{8}$ molecules is operating in toluene- $d_{8}$ solutions of 6 at $300 \mathrm{~K}$. Fast exchange equilibria comprising different Lewis donor and arene molecules have been previously observed in arene solutions of other alkali metal amide species [i.e., [TMEDA. $\left.\mathrm{Li}_{2} \mathrm{~K}(\mathrm{DA})_{3}\right]$ and $\left.[\mathrm{THF} \cdot \mathrm{Li}(\mathrm{TMP})]_{2}\right]^{45,46}$

Complex 6 in toluene- $d_{8}$ solution was studied by ${ }^{1} \mathrm{H}$ VT NMR spectroscopy (Figure 7). As alluded to earlier, the ${ }^{1} \mathrm{H}$ NMR spectrum of a toluene- $d_{8}$ solution of 6 at $300 \mathrm{~K}$ suggests that the TMEDA ligand is not bound to the cesium metal amide. However, as the temperature is decreased to $203 \mathrm{~K}$, the data suggest that the "donor" TMEDA molecule does bind to the cesium metal complex. In addition, the ${ }^{133} \mathrm{Cs}$ NMR spectrum of 6 in toluene- $d_{8}$ solution is similar to that of CsHMDS in the same solvent at $300 \mathrm{~K}$ (126.8 vs $123.0 \mathrm{ppm}$, respectively), and it is shifted as the temperature decreased to 203 K (156.1 ppm; see Supporting Information).

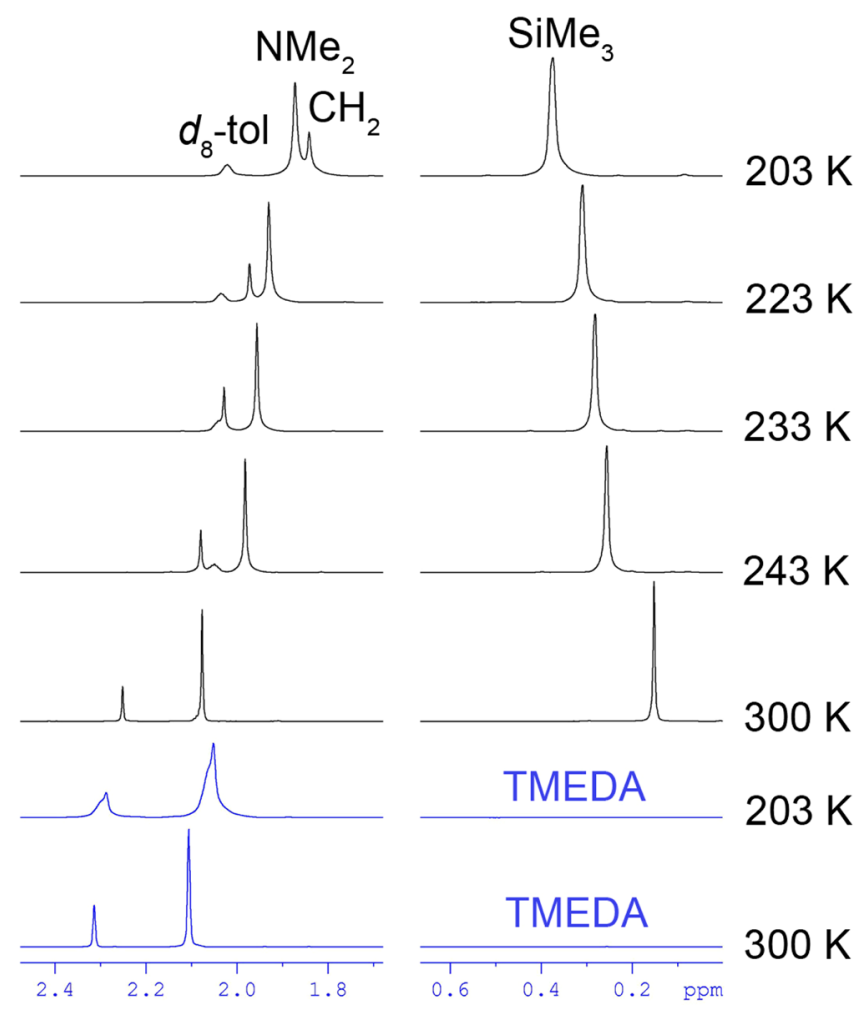

Figure 7. Variable temperature ${ }^{1} \mathrm{H}$ NMR study of a solution of 6 in toluene- $d_{8}$ from 300 to $203 \mathrm{~K}$, showing coordination of TMEDA binding to CsHMDS at $203 \mathrm{~K} .{ }^{1} \mathrm{H}$ NMR spectra of uncoordinated TMEDA at 300 and $203 \mathrm{~K}$ are shown in blue.

To show that this is a genuine effect caused by the cesium metal species, a ${ }^{1} \mathrm{H}$ VT NMR spectroscopic study of a sample of TMEDA in toluene- $d_{8}$ was also carried out. The data show that the chemical shifts of the free bidentate ligand are not altered in this experiment in comparison with the ${ }^{1} \mathrm{H}$ VT NMR spectroscopic study of 6 in the same solvent (Figure 7). In addition, the 1:1 CsHMDS/TMEDA ratio is maintained for 6 in toluene- $d_{8}$ solution at the variety of temperatures studied (in the range $300-203 \mathrm{~K}$ ).

Turning to 8, only a single ${ }^{1} \mathrm{H}$ NMR HMDS resonance at 0.24 (and ${ }^{13} \mathrm{C}$ NMR at $7.4 \mathrm{ppm}$ ) is observed in $\mathrm{C}_{6} \mathrm{D}_{6}$ solution at $300 \mathrm{~K}$, contrasting with the presence of two distinct HMDS ligands within the solid state structure of 8 . In addition, the resonances for the tetra-dentate $\mathrm{Me}_{6}$ TREN ligand in $\mathbf{8}$ are close to that of free $\mathrm{Me}_{6}$ TREN in the ${ }^{1} \mathrm{H}$ NMR spectrum in $\mathrm{C}_{6} \mathrm{D}_{6}$ at $300 \mathrm{~K}\left[\mathrm{Me}_{6}\right.$ TREN in 8: $2.09(\mathrm{Me}), 2.29\left(\beta-\mathrm{CH}_{2}\right)$ and 2.53 ppm $\left(\alpha-\mathrm{CH}_{2}\right)$; free $\mathrm{Me}_{6}$ TREN: $2.12(\mathrm{Me}), 2.37\left(\beta-\mathrm{CH}_{2}\right)$, and $\left.2.63 \mathrm{ppm}\left(\alpha-\mathrm{CH}_{2}\right)\right]$. In keeping with 6 , these data suggest deaggregation of dimeric tetranuclear 8 in $\mathrm{C}_{6} \mathrm{D}_{6}$ solution at 300 $\mathrm{K}$. To ascertain the aggregation state of $\mathbf{8}$ in arene solutions, a crystalline sample of $\mathbf{8}$ was treated with toluene- $d_{8}$ and a ${ }^{1} \mathrm{H}$ DOSY NMR spectroscopic study was carried out at $300 \mathrm{~K}$. The distinct diffusion coefficients observed for the HMDS and $\mathrm{Me}_{6}$ TREN ligands $\left(9.038 \times 10^{-10}\right.$ and $1.0148 \times 10^{-9} \mathrm{~m}^{2} \mathrm{~s}^{-1}$, respectively) indicate partial decoordination of the "donor" $\mathrm{Me}_{6}$ TREN ligand from the cesium metal amide, thus suggesting the presence of a competition process between toluene- $d_{8}$ and $\mathrm{Me}_{6}$ TREN molecules to coordinate the cesium cation.

In the monomeric complex 9, a single resonance at $0.51 \mathrm{ppm}$ is observed in the ${ }^{1} \mathrm{H}$ NMR spectrum in $\mathrm{C}_{6} \mathrm{D}_{6}$ solution at $300 \mathrm{~K}$ for the $\mathrm{SiMe}_{3}$ group (7.6 ppm in the ${ }^{13} \mathrm{C}$ NMR spectrum). The 
chemical shifts for the resonances of the heptadentate TMEEA ligand in 9 are different to those of the free Lewis base ligand both in the ${ }^{1} \mathrm{H}$ and ${ }^{13} \mathrm{C}$ NMR spectra in the same conditions (see Table S1). To further study the aggregation state of 9 (to determine whether the TMEEA ligand is coordinated to the cesium HMDS reagent in 9 in arene solutions), a ${ }^{1} \mathrm{H}$ DOSY NMR study was carried out in toluene- $d_{8}$ at $300 \mathrm{~K}$. The coefficient diffusion values obtained indicate the presence of a species with an intermediate molecular weight between [TMEEA.CsHMDS] 9 and [(toluene- $\left.d_{8}\right)_{n} \cdot$ CsHMDS] (see Supporting Information for full details). Mirroring the solution behavior observed for 6 and 8 in the same conditions, this result is in agreement with the presence of a dynamic process involving the competition between the TMEEA ligand and toluene- $d_{8}$ molecules to coordinate the cesium cation in toluene- $d_{8}$ solution at $300 \mathrm{~K}$.

\section{CONCLUSIONS}

By combining commercially available/easily prepared LiHMDS with CsF, the cesium amide CsHMDS has been prepared in a facile manner, which negates the use of pyrophoric cesium metal. The CsHMDS can then be utilized as a reagent by combining it with lighter alkali metal ( $\mathrm{Li}$ or $\mathrm{Na}$ ) HMDS complexes to cocomplex the two reagents to produce polymeric mixed alkali metal amide species. In addition, by judicious choice of donor ligand, it has been shown that CsHMDS can display a variety of oligomerization states-closed dimeric [with $(R, R)$-TMCDA, TMEDA, or PMDETA], tetranuclear open dimeric (with $\mathrm{Me}_{6}$-TREN), and a rare example of a monomeric cesium amide (with TMEEA). Given the current interest in CsHMDS in synthetic organic chemistry, and indeed the use of heavier alkali metal amides in super basic mixtures, future studies will assess the reactivity of these reagents in this area.

\section{EXPERIMENTAL SECTION}

Crystallographic Analysis. Crystallographic data were recorded on Oxford Diffraction Xcalibur and Gemini diffractometers with $\mathrm{Cu}-$ $\mathrm{K} \alpha$ radiation $(\lambda=1.5418 \AA)$ for 2 and 3 and $\mathrm{Mo}-\mathrm{K} \alpha$ radiation $(\lambda=$ $0.71073 \AA)$ for the other structures. Measurements were made at 123(2) K except for 6 where measurements were made at 150(2) K. Structures were refined to convergence on $F^{2}$ and against all independent reflections by full-matrix least-squares using SHELXL2013. ${ }^{47}$ The geometries of the disordered groups were restrained to approximate typical values. An analytical absorption correction was applied in 3 using a multifaceted crystal model ${ }^{48}$ and spherical harmonics implemented in SCALE3 ABSPACK scaling algorithm (CrysAlisPro, Oxford Diffraction Ltd.). Selected crystallographic parameters are given in Tables S2 and S3 and full details are given in the deposited cif files (CCDC 1447680-1447686 for 2, 3, and 5-9, respectively). These data in cif format can be obtained free of charge from the Cambridge Crystallographic Data Centre via http://www. ccdc.cam.ac.uk/data_request/cif.

General Procedures. All reactions were performed under argon atmosphere using standard Schlenk techniques. $n$-Hexane, toluene, and tetrahydrofuran (THF) were distilled under reflux with sodium metal and benzophenone within a nitrogen atmosphere. $\mathrm{C}_{6} \mathrm{D}_{6}$ was degassed and stored under argon over activated molecular sieves $(4 \AA)$ prior to use. Bis(trimethylsilyl)amine $[\operatorname{HMDS}(\mathrm{H})], N, N, N^{\prime}, N^{\prime}$ tetramethylethylenediamine (TMEDA), and $N, N, N^{\prime}, N^{\prime \prime}, N^{\prime \prime}$-pentamethyldiethylenetriamine (PMDETA) were purchased from Aldrich, distilled under nitrogen atmosphere with $\mathrm{CaH}_{2}$, and stored under argon over activated molecular sieves $(4 \AA)$. Tris $\{2$-(dimethylamino)ethyl $\}$ amine $\left(\mathrm{Me}_{6}\right.$ TREN) and $(R, R)-N, N, N^{\prime}, N^{\prime}$-tetramethylcyclohexane-1,2-diamine $[(R, R)$-TMCDA $]$ were prepared according to literature methods, and stored under argon over activated molecular sieves (4 Å). Tris $\{2$-(2-methoxyethoxy)ethyl $\}$ amine (TMEEA) was purchased from Aldrich and used as received. $\mathrm{CsF}$ was purchased from Aldrich and dried under vacuum at $150{ }^{\circ} \mathrm{C}$ for 5 days and stored in a glovebox. LiHMDS was prepared reacting $n$-BuLi and $\operatorname{HMDS}(\mathrm{H})$ according to literature methods and stored in a glovebox. NMR spectra were recorded on a Bruker DPX $400 \mathrm{MHz}$ spectrometer, operating at 400.1, 100.6, and 52.5 for ${ }^{1} \mathrm{H},{ }^{13} \mathrm{C}$ and ${ }^{133} \mathrm{Cs}$, respectively. ${ }^{1} \mathrm{H}$ and ${ }^{13} \mathrm{C}\left\{{ }^{1} \mathrm{H}\right\}$ NMR chemical shifts are expressed in parts per million (ppm) and referenced to residual solvent peaks. ${ }^{133} \mathrm{Cs}$ NMR spectra were referenced against an external standard solution of CsF (1 $\mathrm{M}$ in $\mathrm{D}_{2} \mathrm{O}, \delta=0 \mathrm{ppm}$ ). Microanalysis was obtained for all compounds using a PerkinElmer 2400 elemental analyzer.

Synthesis of CsHMDS (1). A $1.6 \mathrm{M}$ solution of $n$-BuLi in hexanes $(18.75 \mathrm{~mL}, 30 \mathrm{mmol})$ was added dropwise to a solution of $\operatorname{HMDS}(\mathrm{H})$ $(6.3 \mathrm{~mL}, 30 \mathrm{mmol})$ in $n$-hexane $(40 \mathrm{~mL})$ and the reaction was stirred for $2 \mathrm{~h}$. CsF $(4.56 \mathrm{mg}, 30 \mathrm{mmol})$ was added using a solid addition tube, and the reaction mixture was refluxed for $15 \mathrm{~h}$ at $68^{\circ} \mathrm{C}$ to yield a pale gray suspension. The reaction was cooled to ambient temperature, the solvent removed under a vacuum, and toluene $(60 \mathrm{~mL})$ was added. The reaction was filtered and the solid washed with toluene $(2 \times 15$ $\mathrm{mL})$. The solvent of the colorless solution was removed under a vacuum and the resultant white product was sublimed $\left(200{ }^{\circ} \mathrm{C}, 5 \mathrm{~h}\right)$ to yield white crystals of 1 . Yield: $7 \mathrm{~g}, 23.87 \mathrm{mmol}, 80 \% .{ }^{1} \mathrm{H}$ NMR $\left(400.01 \mathrm{MHz}, 300 \mathrm{~K}, \mathrm{C}_{6} \mathrm{D}_{6}\right): \delta 0.21(\mathrm{~s}, 18 \mathrm{H}) .{ }^{13} \mathrm{C}\left\{{ }^{1} \mathrm{H}\right\}$ NMR $(100.6$ $\left.\mathrm{MHz}, 300 \mathrm{~K}, \mathrm{C}_{6} \mathrm{D}_{6}\right): \delta 7.3 .{ }^{133} \mathrm{Cs} \mathrm{NMR}\left(52.5 \mathrm{MHz}, \mathrm{C}_{6} \mathrm{D}_{6}, 300 \mathrm{~K}\right): \delta$ 119.2 (s). Anal. Calcd (Found) for $\mathrm{C}_{6} \mathrm{H}_{18} \mathrm{CsNSi}_{2}$ : C, 24.57 (24.61); H, 6.19 (6.19); N, 4.78\% (4.91\%).

Synthesis of $\left[\mathrm{LiCs}(H M D S)_{2}\right]_{\infty}$ (2). LiHMDS (670 mg, $\left.4 \mathrm{mmol}\right)$ was suspended in $n$-hexane $(20 \mathrm{~mL})$ and cesium fluoride $(304 \mathrm{mg}, 2$ $\mathrm{mmol}$ ) added using a solid addition tube. The reaction was refluxed for $8 \mathrm{~h}$ at $68{ }^{\circ} \mathrm{C}$, and the solvent was evacuated to dryness. Toluene $(10$ $\mathrm{mL}$ ) was added and the reaction was heated and filtered obtaining a colorless solution. Crystals of $\mathbf{2}$ suitable for X-ray study crystallized at $-33{ }^{\circ} \mathrm{C}$ from a $n$-hexane/toluene $(7 / 5 \mathrm{~mL})$ mixture after $24 \mathrm{~h}$. Compound 2 was filtered, washed with $n$-hexane $(10 \mathrm{~mL})$ and dried under a vacuum for $10 \mathrm{~min}$. Yield (based on the consumption of $\mathrm{CsF}$ ): $520 \mathrm{mg}, 1.13 \mathrm{mmol}, 57 \% .{ }^{1} \mathrm{H}$ NMR $\left(400.01 \mathrm{MHz}, 300 \mathrm{~K}, \mathrm{C}_{6} \mathrm{D}_{6}\right): \delta$ $0.27(\mathrm{~s}, 36 \mathrm{H}) .{ }^{13} \mathrm{C}\left\{{ }^{1} \mathrm{H}\right\}$ NMR $\left(100.6 \mathrm{MHz}, 300 \mathrm{~K}, \mathrm{C}_{6} \mathrm{D}_{6}\right): \delta 6.7 .{ }^{7} \mathrm{Li}$ NMR (155.47 MHz, $\left.300 \mathrm{~K}, \mathrm{C}_{6} \mathrm{D}_{6}\right): \delta 1.8 .{ }^{133} \mathrm{Cs}$ NMR $(52.5 \mathrm{MHz}$, $\mathrm{C}_{6} \mathrm{D}_{6}, 300 \mathrm{~K}$ ): $\delta 54.2$ (v br s). Anal. Calcd (Found) for $\mathrm{C}_{12} \mathrm{H}_{36} \mathrm{CsLiN}_{2} \mathrm{Si}_{4}$ : C, 31.29 (32.02); H, 7.88 (8.02); N, 6.08\% (6.04\%).

Synthesis of [toluene. $\left.\mathrm{NaCs}(\mathrm{HMDS})_{2}\right]_{\infty}$ (3). NaHMDS (184 mg, 1 $\mathrm{mmol})$ and CsHMDS (293 mg, $1 \mathrm{mmol})$ were suspended in $n$-hexane $(10 \mathrm{~mL})$, and the reaction mixture was stirred for $5 \mathrm{~min}$. Toluene $(2$ $\mathrm{mL}$ ) was added to obtain a colorless solution and the reaction was stored at $-33{ }^{\circ} \mathrm{C}$ where 3 crystallized as colorless crystals suitable for an X-ray diffraction study after 24 h. 3 was filtered, washed with $n$ hexane $(10 \mathrm{~mL})$, and dried under a vacuum for $3 \mathrm{~min}$. Yield: $350 \mathrm{mg}$, $0.62 \mathrm{mmol}, 62 \% .{ }^{1} \mathrm{H}$ NMR $\left(400.1 \mathrm{MHz}, \mathrm{C}_{6} \mathrm{D}_{6}, 300 \mathrm{~K}\right): \delta 0.18(\mathrm{~s}, 36$ $\left.\mathrm{H}, \mathrm{Me}_{3} \mathrm{Si}\right), 2.11$ (s, $3 \mathrm{H}$, Me-toluene), $7.02(\mathrm{~m}, 3 \mathrm{H}$, ortho + para- $\mathrm{CH})$, $7.13(\mathrm{~m}, 2 \mathrm{H}$, meta-CH$) .{ }^{13} \mathrm{C}\left\{{ }^{1} \mathrm{H}\right\}$ NMR $\left(100.6 \mathrm{MHz}, \mathrm{C}_{6} \mathrm{D}_{6}, 300 \mathrm{~K}\right): \delta$ 7.3 ( $\left.\mathrm{Me}_{3} \mathrm{Si}\right), 21.5$ (Me-toluene), 125.7 (para-CH), 128.6 (meta- $\left.\mathrm{CH}\right)$, 129.3 (ortho-CH), 137.9 (C-toluene). ${ }^{133} \mathrm{Cs}$ NMR (52.5 MHz, $\mathrm{C}_{6} \mathrm{D}_{6}$, $300 \mathrm{~K}$ ): $\delta 92.0$ (v br s). Anal. Calcd (Found) for $\mathrm{C}_{12} \mathrm{H}_{36} \mathrm{CsN}_{2} \mathrm{NaSi}_{4}: \mathrm{C}$, 30.24 (29.90); H, 7.61 (7.52); N, 5.88\% (5.69\%).

Synthesis of $[(R, R)-T M C D A \cdot C s H M D S]_{2}$ (5). CsHMDS (293 mg, 1 mmol) was suspended in $n$-hexane $(10 \mathrm{~mL})$, and the reaction mixture was stirred for $10 \mathrm{~min}$. After that, $(R, R)$-TMCDA $(0.19 \mathrm{~mL}, 1 \mathrm{mmol})$ was added to yield a colorless solution. The reaction was filtered via cannula, and the solution was stored at $-33^{\circ} \mathrm{C}$ where 5 crystallized as colorless crystals suitable for an X-ray diffraction study after $24 \mathrm{~h}$. Compound 5 was filtered, washed with $n$-hexane $(10 \mathrm{~mL})$, and dried under a vacuum for $5 \mathrm{~min}$. Yield: $190 \mathrm{mg}, 0.21 \mathrm{mmol}, 41 \% .{ }^{1} \mathrm{H}$ NMR $\left(400.1 \mathrm{MHz}, \mathrm{C}_{6} \mathrm{D}_{6}, 300 \mathrm{~K}\right): \delta 0.25\left(\mathrm{~s}, 18 \mathrm{H}, \mathrm{Me}_{3} \mathrm{Si}\right), 0.97(\mathrm{~s}, 4 \mathrm{H}, \beta / \gamma$ $\mathrm{CH}_{2}-(R, R)$-TMCDA), $1.58\left(\mathrm{~s}, 2 \mathrm{H}, \beta / \gamma-\mathrm{CH}_{2}-(R, R)-\mathrm{TMCDA}\right), 1.72$ $\left(\mathrm{s}, 2 \mathrm{H}, \beta / \gamma-\mathrm{CH}_{2}-(R, R)-\mathrm{TMCDA}\right), 2.2(\mathrm{~s}, 2 \mathrm{H}, \alpha-\mathrm{CH}-(R, R)-$ TMCDA ), 2.23 (s, $12 \mathrm{H}, \mathrm{Me}-(R, R)$-TMCDA). ${ }^{13} \mathrm{C}\left\{{ }^{1} \mathrm{H}\right\}$ NMR $\left(100.6 \mathrm{MHz}, \mathrm{C}_{6} \mathrm{D}_{6}, 300 \mathrm{~K}\right): \delta 7.4\left(\mathrm{Me}_{3} \mathrm{Si}\right), 25.1\left(\beta-\mathrm{CH}_{2}-(R, R)-\right.$ TMCDA), 25.9 ( $\gamma$ - $\left.\mathrm{CH}_{2}-(R, R)-\mathrm{TMCDA}\right), 40.5$ (Me-(R,R)-TMCDA), 
$64.3(\alpha-\mathrm{CH}-(R, R)-\mathrm{TMCDA}) .{ }^{133} \mathrm{Cs}$ NMR $\left(52.5 \mathrm{MHz}, \mathrm{C}_{6} \mathrm{D}_{6}, 300 \mathrm{~K}\right)$ : $\delta 123.19$ (br s). Anal. Calcd (Found) for $\mathrm{C}_{32} \mathrm{H}_{80} \mathrm{Cs}_{2} \mathrm{~N}_{6} \mathrm{Si}_{4}$ : C, 41.45 (41.46); H, 8.70 (8.64); N, 9.06\% (9.35\%).

Synthesis of [TMEDA.CsHMDS] 2 (6). CsHMDS (587 mg, $2 \mathrm{mmol}$ ) was suspended in $n$-hexane $(10 \mathrm{~mL})$, and the reaction mixture was stirred for $10 \mathrm{~min}$. After that, TMEDA $(0.3 \mathrm{~mL}, 2 \mathrm{mmol})$ was added to yield a colorless solution. The reaction was filtered via cannula, concentrated $(5 \mathrm{~mL})$, and stored at $-33{ }^{\circ} \mathrm{C}$ where 6 crystallized as colorless crystals suitable for an X-ray diffraction study after $24 \mathrm{~h}$. Compound 6 was filtered, washed with $n$-hexane $(10 \mathrm{~mL})$, and dried under a vacuum for $5 \mathrm{~min}$. Yield: $170 \mathrm{mg}, 0.21 \mathrm{mmol}, 21 \% .{ }^{1} \mathrm{H}$ NMR $\left(400.1 \mathrm{MHz}, \mathrm{C}_{6} \mathrm{D}_{6}, 300 \mathrm{~K}\right): \delta 0.23\left(\mathrm{~s}, 36 \mathrm{H}, \mathrm{Me}_{3} \mathrm{Si}\right), 2.08(\mathrm{~s}, 24 \mathrm{H}$, $\mathrm{CH}_{3}$-TMEDA), 2.28 (s, $8 \mathrm{H}, \mathrm{CH}_{2}$-TMEDA). ${ }^{13} \mathrm{C}\left\{{ }^{1} \mathrm{H}\right\}$ NMR (100.6 $\left.\mathrm{MHz}, \mathrm{C}_{6} \mathrm{D}_{6}, 300 \mathrm{~K}\right): \delta 7.3\left(\mathrm{Me}_{3} \mathrm{Si}\right), 45.9\left(\mathrm{CH}_{3}\right.$-TMEDA), $58.2\left(\mathrm{CH}_{2}-\right.$ TMEDA). ${ }^{133} \mathrm{Cs}$ NMR $\left(52.5 \mathrm{MHz}, \mathrm{C}_{6} \mathrm{D}_{6}, 300 \mathrm{~K}\right): \delta 126.2(\mathrm{~s})$. According to ${ }^{1} \mathrm{H}$ NMR there is a deficit of ligand molecules with respect to CsHMDS (1.61 molecules of TMEDA vs 2 molecules of TMEDA found in solid state) due to evacuation of some molecules of the ligand while drying 6. Anal. Calcd (Found) for $\mathrm{C}_{21.78} \mathrm{H}_{62.08} \mathrm{Cs}_{2} \mathrm{~N}_{5.26} \mathrm{Si}_{4}:$ C, 33.71 (33.56); H, 8.06 (7.82); N, 9.49\% $(9.28 \%)$.

Synthesis of [PMDETA.CsHMDS] 2 (7). CsHMDS ( $587 \mathrm{mg}, 2 \mathrm{mmol})$ was suspended in $n$-hexane $(10 \mathrm{~mL})$, and the reaction mixture was stirred for $10 \mathrm{~min}$. After that, PMDETA $(0.42 \mathrm{~mL}, 2 \mathrm{mmol})$ was added, and the reaction heated with a hot gun and placed inside a hot water bath where 7 crystallized as colorless crystals suitable for an Xray after $24 \mathrm{~h} .7$ was filtered, washed with $n$-hexane $(15 \mathrm{~mL})$ and dried under a vacuum for $5 \mathrm{~min}$. Yield: $620 \mathrm{mg}, 0.68 \mathrm{mmol}, 68 \%$. ${ }^{1} \mathrm{H}$ NMR $\left(400.1 \mathrm{MHz}, 300 \mathrm{~K}, \mathrm{C}_{6} \mathrm{D}_{6}\right): \delta 0.27\left(\mathrm{~s}, 18 \mathrm{H}, \mathrm{SiCH}_{3}\right), 2.09(\mathrm{~s}, 12 \mathrm{H}$, $\mathrm{Me}_{2} \mathrm{~N}$-PMDETA), 2.12 (s, $3 \mathrm{H}, \mathrm{MeN}$-PMDETA), 2.25 (m, 4H, $\mathrm{CH}_{2}-$ PMDETA), 2.34 (m, 4H, CH $\mathrm{CH}_{2}$ PMDTA). ${ }^{13} \mathrm{C}\left\{{ }^{1} \mathrm{H}\right\}$ NMR (100.6 $\left.\mathrm{MHz}, 300 \mathrm{~K}, \mathrm{C}_{6} \mathrm{D}_{6}\right): \delta 7.4\left(\mathrm{SiCH}_{3}\right), 42.8$ (MeN-PMDETA), 45.8 ( $\mathrm{Me}_{2} \mathrm{~N}$-PMDETA), 56.7 ( $\mathrm{CH}_{2}$-PMDETA), 58.0 ( $\mathrm{CH}_{2}$-PMDETA). ${ }^{133} \mathrm{Cs}$ NMR $\left(52.5 \mathrm{MHz}, \mathrm{C}_{6} \mathrm{D}_{6}, 300 \mathrm{~K}\right): \delta 129.7$ (s). Anal. Calcd (Found) for $\mathrm{C}_{30} \mathrm{H}_{82} \mathrm{Cs}_{2} \mathrm{~N}_{8} \mathrm{Si}_{4}$ : C, 38.61 (38.79); H, 8.86 (9.04); N, $12.01 \%(12.14 \%)$.

Synthesis of $\left[\left(\mathrm{Me}_{6} \text { TREN.CSHMDS }\right)_{2}(\mathrm{CsHMDS})_{2}\right]$ (8). CsHMDS (587 $\mathrm{mg}, 2 \mathrm{mmol})$ was suspended in $n$-hexane $(10 \mathrm{~mL})$, and the reaction mixture was stirred for $10 \mathrm{~min} . \mathrm{Me}_{6}$ TREN $(0.27 \mathrm{~mL}, 1 \mathrm{mmol})$ was added, and the reaction was stirred for $10 \mathrm{~min}$ to yield an orange suspension. Crystals of $\mathbf{8}$ suitable for an X-ray diffraction study grow from a mixture of $n$-hexane/toluene $(5 / 8 \mathrm{~mL})$ at $-33{ }^{\circ} \mathrm{C}$ after 1 month. Compound 8 was filtered, washed with $n$-hexane $(3 \times 3 \mathrm{~mL})$ and dried under a vacuum for $5 \mathrm{~min}$. Yield: $410 \mathrm{mg}, 0.25 \mathrm{mmol}, 50 \%$. ${ }^{1} \mathrm{H}$ NMR (400.1 MHz, $\left.\mathrm{C}_{6} \mathrm{D}_{6}, 300 \mathrm{~K}\right): \delta 0.24\left(\mathrm{~s}, 36 \mathrm{H}, \mathrm{Me}_{3} \mathrm{Si}\right), 2.09(\mathrm{~s}$, $\left.18 \mathrm{H}, \mathrm{Me}-\mathrm{Me}_{6} \mathrm{TREN}\right), 2.29\left(\mathrm{t}, 6 \mathrm{H},{ }^{3} J_{\mathrm{HH}}=6.7 \mathrm{~Hz}, \alpha / \beta-\mathrm{CH}_{2}-\right.$ $\mathrm{Me}_{6}$ TREN), $2.53\left(\mathrm{t}, 6 \mathrm{H},{ }^{3} J_{\mathrm{HH}}=5.07 \mathrm{~Hz}, \alpha / \beta-\mathrm{CH}_{2}-\mathrm{Me}_{6}\right.$ TREN). ${ }^{13} \mathrm{C}\left\{{ }^{1} \mathrm{H}\right\}$ NMR $\left(100.6 \mathrm{MHz}, \mathrm{C}_{6} \mathrm{D}_{6}, 300 \mathrm{~K}\right): \delta 7.4\left(\mathrm{Me}_{3} \mathrm{Si}\right), 45.9(\mathrm{Me}-$ $\mathrm{Me}_{6}$ TREN), 53.3 ( $\alpha / \beta-\mathrm{CH}_{2}-\mathrm{Me}_{6}$ TREN), $58.2\left(\alpha / \beta-\mathrm{CH}_{2}-\mathrm{Me}_{6}\right.$ TREN). ${ }^{133} \mathrm{Cs}$ NMR (52.5 MHz, $\left.\mathrm{C}_{6} \mathrm{D}_{6}, 300 \mathrm{~K}\right): \delta 124.56$ (br s). According to ${ }^{1} \mathrm{H}$ NMR there are 0.54 molecules of toluene per complex. Anal. Calcd (Found) for $\mathrm{C}_{51.78} \mathrm{H}_{136.32} \mathrm{Cs}_{4} \mathrm{~N}_{12} \mathrm{Si}_{8}$ : C, 36.94 (37.55); H, 8.16 (8.00); N, $9.98 \%(10.09 \%)$.

Synthesis of [TMEEA.Cs(HMDS)] (9). CsHMDS (587 mg, $2 \mathrm{mmol}$ ) was suspended in $n$-hexane $(10 \mathrm{~mL})$, and the reaction mixture was stirred for $10 \mathrm{~min}$. TMEEA $(0.64 \mathrm{~mL}, 2 \mathrm{mmol})$ was added, and the reaction was stirred for $10 \mathrm{~min}$ to yield a brown oily material. Crystals of 9 crystallized from a hexane/toluene $(6 / 5 \mathrm{~mL})$ mixture at $-33^{\circ} \mathrm{C}$ after 3 days. Compound 9 was filtered, washed with $n$-hexane $(15 \mathrm{~mL})$, and dried under a vacuum for $5 \mathrm{~min}$. Yield: $600 \mathrm{mg}, 0.97 \mathrm{mmol}, 49 \%$. ${ }^{1} \mathrm{H}$ NMR (400.1 MHz, $\left.\mathrm{C}_{6} \mathrm{D}_{6}, 300 \mathrm{~K}\right): \delta 0.51\left(\mathrm{~s}, 18 \mathrm{H}, \mathrm{Me}_{3} \mathrm{Si}\right), 2.30(\mathrm{t}$, $6 \mathrm{H}^{3} \mathrm{~J}_{\mathrm{HH}}=5.07 \mathrm{~Hz}, \mathrm{CH}_{2} \mathrm{~N}$-donor $), 3.15\left(\mathrm{t}, 6 \mathrm{H},{ }^{3} \mathrm{~J}_{\mathrm{HH}}=5.07 \mathrm{~Hz}, \mathrm{CH}_{2^{-}}\right.$ donor), 3.21 (s, $9 \mathrm{H}, \mathrm{CH}_{3}$-donor), $3.26\left(\mathrm{~m}, 6 \mathrm{H}, \mathrm{CH}_{2}\right.$-donor), 3.28 (m, $6 \mathrm{H}, \mathrm{CH}_{2}$-donor). ${ }^{13} \mathrm{C}\left\{{ }^{1} \mathrm{H}\right\}$ NMR $\left(100.6 \mathrm{MHz}, \mathrm{C}_{6} \mathrm{D}_{6}, 300 \mathrm{~K}\right): \delta$ $7.6\left(\mathrm{Me}_{3} \mathrm{Si}\right), 55.5\left(\mathrm{CH}_{2} \mathrm{~N}\right.$-donor $), 58.7\left(\mathrm{CH}_{3}\right.$-donor $), 69.0\left(\mathrm{CH}_{2}-\right.$ donor), 70.4 ( $\mathrm{CH}_{2}$-donor), 72.0 ( $\mathrm{CH}_{2}$-donor). ${ }^{133} \mathrm{Cs} \mathrm{NMR}(52.5$ $\left.\mathrm{MHz}, \mathrm{C}_{6} \mathrm{D}_{6}, 300 \mathrm{~K}\right): \delta 104.0$ (s). Anal. Calcd (Found) for $\mathrm{C}_{21} \mathrm{H}_{51} \mathrm{CsN}_{2} \mathrm{O}_{6} \mathrm{Si}_{2}$ : C, 40.90 (41.11); $\mathrm{H}, 8.34$ (8.24); N, $4.54 \%$ (4.70\%)

\section{ASSOCIATED CONTENT}

\section{Supporting Information}

The Supporting Information is available free of charge on the ACS Publications website at DOI: 10.1021/acs.inorgchem.6b00839.

${ }^{1} \mathrm{H},{ }^{133} \mathrm{Cs}$, and ${ }^{13} \mathrm{C}\left\{{ }^{1} \mathrm{H}\right\}$ NMR spectra for complexes 1-9 (PDF)

Crystallographic data for complexes 2, 3, and 5-9 (CIF)

\section{AUTHOR INFORMATION}

\section{Corresponding Author}

*E-mail: charlie.ohara@strath.ac.uk. Tel: +44 (0) 141548 2667.

\section{Funding}

We are grateful to the UK Engineering and Physical Sciences Research Council (J001872/1 and L001497/1) for the award of a Career Acceleration Fellowship to CTO. The research data associated with this paper is available at http://dx.doi.org/10. 15129/a1e25028-54cc-4042-82b0-87554f9648ad.

\section{Notes}

The authors declare no competing financial interest.

\section{ACKNOWLEDGMENTS}

We thank Professor Robert E. Mulvey and Professor Eva Hevia for thoughtful discussions.

\section{DEDICATION}

In memory of Professor Malcolm H. Chisholm, a truly inspirational and generous gentleman.

\section{REFERENCES}

(1) Mulvey, R. E.; Robertson, S. D. Angew. Chem., Int. Ed. 2013, 52, 11470-11487.

(2) (a) Godenschwager, P. F.; Collum, D. B. J. Am. Chem. Soc. 2007, 129, 12023-12031. (b) Kauffman, G. S.; Harris, G. D.; Dorow, R. L.; Stone, B. R. P.; Parsons, R. L., Jr.; Pesti, J. A.; Magnus, N. A.; Fortunak, J. M.; Confalone, P. N.; Nugent, W. A. Org. Lett. 2000, 2, 3119. (c) Boys, M. L.; Cain-Janicki, K. J.; Doubleday, W. W.; Farid, P. N.; Kar, M.; Nugent, S. T.; Behling, J. R.; Pilipauskas, D. R. Org. Process Res. Dev. 1997, 1, 233-239. (d) Ragan, J. A.; Murry, J. A.; Castaldi, M. J.; Conrad, A. K.; Jones, B. P.; Li, B.; Makowski, T. W.; McDermott, R.; Sitter, B. J.; White, T. D.; Young, G. R. Org. Process Res. Dev. 2001, 5, 498-507. (e) DeMattei, J. A.; Leanna, M. R.; Li, W.; Nichols, P. J.; Rasmussen, M. W.; Morton, H. E. J. Org. Chem. 2001, 66, 3330-3337. (f) Kim, Y.-J.; Streitwieser, A. Org. Lett. 2002, 4, 573-575. (g) Barton, D. H. R.; Hesse, R. H.; Tarzia, G.; Pechet, M. M. J. Chem. Soc. D 1969, 1497-1498. (h) Rathke, M. W. J. Am. Chem. Soc. 1970, 92, 32223223. (i) Yoshimura, Y.; Kumamoto, H.; Baba, A.; Takeda, S.; Tanaka, H. Org. Lett. 2004, 6, 1793-1795.

(3) Gillett-Kunnath, M.; Teng, W.; Vargas, W.; Ruhlandt-Senge, K. Inorg. Chem. 2005, 44, 4862-4870.

(4) Wetzel, D. M.; Brauman, J. I. J. Am. Chem. Soc. 1988, 110, 83338336.

(5) Streitwieser, A.; Facchetti, A.; Xie, L.; Zhang, X.; Wu, E. C. J. Org. Chem. 2012, 77, 985-990.

(6) (a) Coles, M. P. Coord. Chem. Rev. 2015, 297-298, 2-23. (b) Lappert, M. F.; Raston, C. L.; Skelton, B. W.; White, A. H. J. Chem. Soc., Chem. Commun. 1982, 14-15.

(7) Li, D.; Keresztes, I.; Hopson, R.; Williard, P. G. Acc. Chem. Res. 2009, 42, 270-280.

(8) (a) Lucht, B. L.; Collum, D. B. J. Am. Chem. Soc. 1995, 117, 9863-9874. (b) Lucht, B. L.; Collum, D. B. J. Am. Chem. Soc. 1994, 116, 6009-6010. 
(9) Mootz, D.; Zinnius, A.; Bottcher, B. Angew. Chem., Int. Ed. Engl. 1969, 8, 378.

(10) Rogers, R. D.; Atwood, J. L.; Grüning, R. J. Organomet. Chem. 1978, 157, 229.

(11) Grüning, R.; Atwood, J. L. J. Organomet. Chem. 1977, 137, 101111.

(12) Knizek, J.; Krossing, I.; Nöth, H.; Schwenk, H.; Seifert, T. Chem. Ber. 1997, 130, 1053-1062.

(13) Driess, M.; Pritzkow, H.; Skipinski, M.; Winkler, U. Organometallics 1997, 16, 5108-5112.

(14) (a) Henderson, K. W.; Dorigo, A. E.; Liu, Q.-L.; Williard, P. G. J. Am. Chem. Soc. 1997, 119, 11855. (b) Engelhardt, L.; Jolly, B.; Junk, P.; Raston, C.; Skelton, B.; White, A. Aust. J. Chem. 1986, 39, 13371345. (c) Karl, M.; Seybert, G.; Massa, W.; Harms, K.; Agarwal, S.; Maleika, R.; Stelter, W.; Greiner, A.; Neumüller, W. H. B.; Dehnicke, K. Z. Anorg. Allg. Chem. 1999, 625, 1301-1309. (d) Kimura, B. Y.; Brown, T. L. J. Organomet. Chem. 1971, 26, 57-67. (e) Lappert, M. F.; Slade, M. J.; Singh, A.; Atwood, J. L.; Rogers, R. D.; Shakir, R. J. Am. Chem. Soc. 1983, 105, 302-304.

(15) Neander, S.; Behrens, U.; Olbrich, F. J. Organomet. Chem. 2000, $604,59-67$.

(16) Fleming, F. F.; Shook, B. C. J. Org. Chem. 2002, 67, 2885-2888.

(17) Luo, G.; Luo, Y.; Qu, J. New J. Chem. 2013, 37, 3274-3280.

(18) Ojeda-Amador, A. I.; Martínez-Martínez, A. J.; Kennedy, A. R.; O'Hara, C. T. Inorg. Chem. 2015, 54, 9833-9844.

(19) Neander, S.; Behrens, U. Z. Anorg. Allg. Chem. 1999, 625, 14291434

(20) Antolini, F.; Hitchcock, P. B.; Khvostov, A. V.; Lappert, M. F.

Eur. J. Inorg. Chem. 2003, 2003, 3391-3400.

(21) Ellermann, J.; Bauer, W.; Schütz, M.; Heinemann, F. W.; Moll, M. Monatsh. Chem. 1998, 129, 547-566.

(22) Gemünd, B.; Nöth, H.; Sachdev, H.; Schmidt, M. Chem. Ber. 1996, 129, 1335-1344.

(23) (a) Gregory, K.; Bremer, M.; von Ragué Schleyer, P.; Klusener, P. A. A.; Brandsma, L. Angew. Chem., Int. Ed. Engl. 1989, 28, 12241226. (b) Esbak, H.; Behrens, U. Z. Anorg. Allg. Chem. 2005, 631, $1581-1587$.

(24) Kögel, J. F.; Finger, L. H.; Frank, N.; Sundermeyer, J. Inorg. Chem. 2014, 53, 3839-3846.

(25) (a) Klinkhammer, K. Polyhedron 2002, 21, 587-598. (b) Morris, J. J.; Noll, B. C.; Honeyman, G. W.; O’Hara, C. T.; Kennedy, A. R.; Mulvey, R. E.; Henderson, K. W. Chem. - Eur. J. 2007, 13, 4418-4432. (c) Edelmann, F. T.; Pauer, F.; Wedler, M.; Stalke, D. Inorg. Chem. 1992, 31, 4143-4146.

(26) Clegg, W.; Kennedy, A. R.; Klett, J.; Mulvey, R. E.; Russo, L. Eur. J. Inorg. Chem. 2012, 2012, 2989-2994.

(27) (a) Armstrong, D. R.; Graham, D. V.; Kennedy, A. R.; Mulvey, R. E.; O'Hara, C. T. Chem. - Eur. J. 2008, 14, 8025. (b) Lochmann, L.; Janata, M. Cent. Eur. J. Chem. 2014, 12, 537-548.

(28) Lappert, M. F.; Power, P. P.; Sanger, A. R.; Srivastava, R. C. Metal and Metalloid Amides; Ellis Horwood Ltd., John Wiley \& Sons: New York, 1980; Vol. 2.

(29) (a) Ghotra, J. S.; Hursthouse, M. B.; Welch, A. J. J. Chem. Soc., Chem. Commun. 1973, 669-670. (b) Bürger, H.; Wannagat, U. Monatsh. Chem. 1963, 94, 1007-1012. (c) Bürger, H.; Wannagat, U. Monatsh. Chem. 1964, 95, 1099-1102.

(30) Bradley, D. C.; Ghotra, J. S.; Hart, F. A. J. Chem. Soc., Dalton Trans. 1973, 1021-1023.

(31) Boncella, J. M.; Coston, C. J.; Cammack, J. K. Polyhedron 1991, 10, 769-770.

(32) Wittig, G.; Ludwig, R.; Polster, R. Chem. Ber. 1955, 88, 294301.

(33) (a) Schlosser, M. J. Organomet. Chem. 1967, 8, 9-16. (b) Lochmann, L.; Pospisil, J.; Vodnansky, J.; Trekoval, J.; Lim, D. Collect. Czech. Chem. Commun. 1965, 30, 2187.

(34) (a) Schlosser, M. Angew. Chem. 2005, 117, 380-398.

(b) Lochmann, L. Eur. J. Inorg. Chem. 2000, 2000, 1115-1126.

(c) Schlosser, M. Pure Appl. Chem. 1988, 60, 1627-1634.
(35) (a) Fleming, P.; O'Shea, D. F. J. Am. Chem. Soc. 2011, 133, 1698-1701. (b) Blangetti, M.; Fleming, P.; O’Shea, D. F. J. Org. Chem. 2012, 77, 2870-2877.

(36) Williard, P. G.; Nichols, M. A. J. Am. Chem. Soc. 1991, 113, 9671-9673.

(37) Sott, R.; Granander, J.; Williamson, C.; Hilmersson, G. Chem. Eur. J. 2005, 11, 4785-4792.

(38) Kennedy, A. R.; Mulvey, R. E.; Rowlings, R. B. J. Am. Chem. Soc. 1998, 120, 7816.

(39) Nichols, M. A.; Waldmueller, D.; Williard, P. G. J. Am. Chem. Soc. 1994, 116, 1153-1154.

(40) Boesveld, W. M.; Hitchcock, P. B.; Lappert, M. F.; Liu, D.-S.; Tian, S. Organometallics 2000, 19, 4030-4035.

(41) Morris, J. J.; Noll, B. C.; Henderson, K. W. Acta Crystallogr., Sect. E: Struct. Rep. Online 2007, 63, m2477.

(42) (a) Klinkhammer, K. W.; Klett, J.; Xiong, Y.; Yao, S. Eur. J. Inorg. Chem. 2003, 2003, 3417-3424. (b) Andrikopoulos, P. C.; Armstrong, D. R.; Kennedy, A. R.; Mulvey, R. E.; O'Hara, C. T.; Rowlings, R. B. Eur. J. Inorg. Chem. 2003, 2003, 3354-3362. (c) Gokel, G. W. Chem. Commun. 2003, 9, 2847-2852.

(43) Groom, C. R.; Allen, F. H. Angew. Chem., Int. Ed. 2014, 53, $662-671$.

(44) Neufeld, R.; Stalke, D. Chem. Sci. 2015, 6, 3354-3364.

(45) Armstrong, D. R.; Kennedy, A. R.; Mulvey, R. E.; Robertson, S. D. Dalton Trans. 2013, 42, 3704-3711.

(46) Armstrong, D. R.; García-Álvarez, P.; Kennedy, A. R.; Mulvey, R. E.; Robertson, S. D. Chem. - Eur. J. 2011, 17, 6725-6730.

(47) Sheldrick, G. Acta Crystallogr., Sect. C: Struct. Chem. 2015, 71, $3-8$.

(48) Clark, R. C.; Reid, J. S. Acta Crystallogr., Sect. A: Found. Crystallogr. 1995, 51, 887-897. 